Eastern Illinois University

The Keep

Masters Theses

Student Theses \& Publications

1-1-1995

\title{
A Comparison Of Dietary Intakes Of Title Iii-C Participants On Home-Delivered Meal And Non- Meal Days
}

Katherine Anne Lewis

Eastern Illinois University

This research is a product of the graduate program in Home Economics at Eastern Illinois University. Find out more about the program.

\section{Recommended Citation}

Lewis, Katherine Anne, "A Comparison Of Dietary Intakes Of Title Iii-C Participants On Home-Delivered Meal And Non-Meal Days" (1995). Masters Theses. 450.

http://thekeep.eiu.edu/theses/450

This Thesis is brought to you for free and open access by the Student Theses \& Publications at The Keep. It has been accepted for inclusion in Masters Theses by an authorized administrator of The Keep. For more information, please contact tabruns@eiu.edu. 


\section{A COMPARISON OF DIETARY INTAKES OF TITLE III - C PARTICIPANTS ON HOME - DELIVERED MEAL AND NON-MEAL DAYS}

\section{LEWIS}


TO: Graduate Degree Candidates (who have written formal theses)

SUBJECT: Permission to Reproduce Theses

The University Library is receiving a number of requests from other institutions asking permission to reproduce dissertations for inclusion in their library holdings. Although no copyright laws are involved, we feel that professional courtesy demands that permission be obtained from the author before we allow theses to be copied.

PLEASE SIGN ONE OF THE FOLLOWING STATEMENTS:

Booth Library of Eastern Illinois University has my permission to lend my thesis to a reputable college or university for the purpose of copying it for inclusion in that institution's library or research holdings.
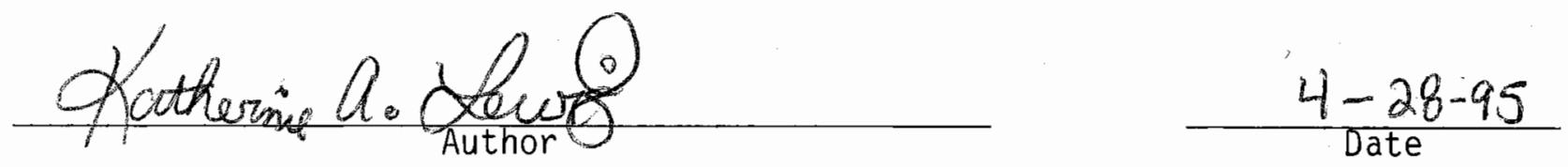

I respectfully request Booth Library of Eastern Illinois University not allow my thesis to be reproduced because: 


\section{A COMPARISON OF DIETARY INTAKES OF TITLE III-C \\ PARTICIPANTS ON HOME-DELIVERED MEAL AND NON-MEAL DAYS. (TITLE)}

$B Y^{\prime}$

Katherine Anne Lewis

\section{THESIS}

SUBMITTED IN PARTIAL FULFILLMENT OF THE REQUIREMENTS FOR THE DEGREE OF

MASTER OF SGIENCE

IN THE GRADUATE SCHOOL, EASTERN ILLINOIS UNIVERSITY

CHARLESTON, ILLINOIS

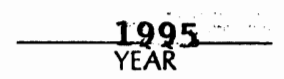

I HEREBY RECOMMEND THIS THESIS BE ACCEPTED AS FULFILLING

THIS PART OF THE GRADUATE DEGREE CITED ABOVE
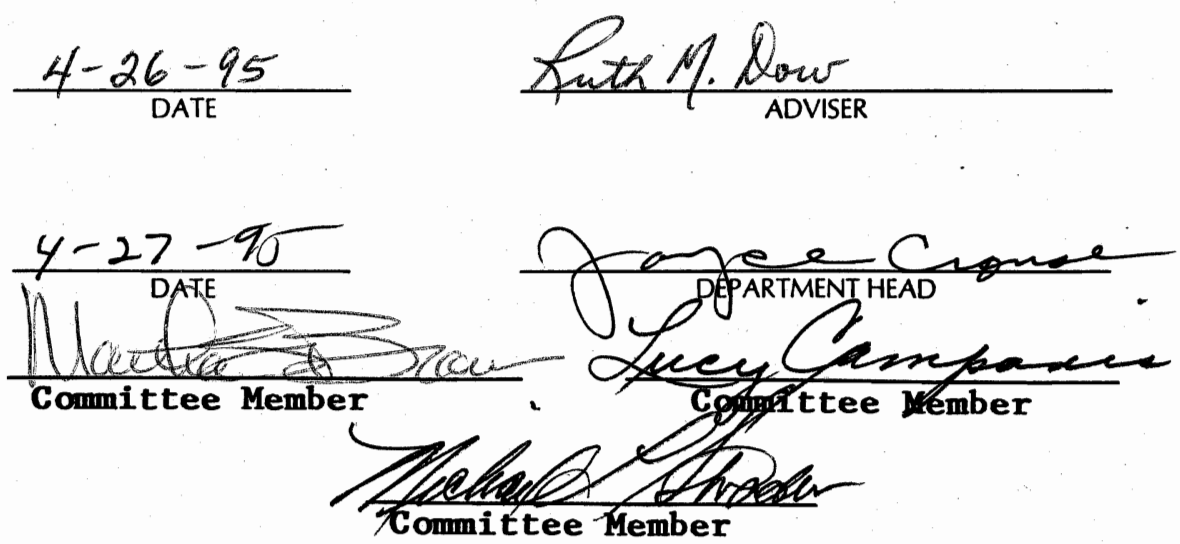
ABSTRACT

Lewis, Katherine A. (1995). A COMPARISON OF DIETARY INTAKES OF TITLE III-C PARTICIPANTS ON HOME-DELIVERED MEAL AND NONMEAL DAYS. Master of Science, Eastern Illinois University. Major professor: Ruth Dow, Ph.D., R.D., C.H.E., F.A.D.A.

Many older Americans may be at risk for malnutrition due to various physiological, socioeconomic, and psychological factors which may affect food consumption. Title III-C of the older Americans Act was established to provide older persons, 60 years and older, with low-cost, nutritious, congregate and home-delivered meals. Two important areas to be addressed concerning participants receiving home-delivered meals are 1) whether the recipients' diets are meeting the 1989 Recommended Dietary Allowances (RDAs) for the age group, 51 years and older, and 2) whether home-delivered meal recipients are safely storing unconsumed foods from these meals. The purposes of this study were to assess and compare the diets of those receiving home-delivered meals in a Title III-C nutrition program on a day of meal delivery and a day of no meal delivery, and to assess some food safety practices of recipients. Trained interviewers collected data in two home interviews with 101 older adults receiving home-delivered meals. Mean intakes indicated that most participants were at low nutritional risk on home-delivered meal days (92\%) and on non-meal days (78\%). The diets of participants were 
better on home-delivered meal days in comparison to non-meal days, based on the 1989 RDAs for adults 51 years and older. Individual nutrients identified as of concern due to less than recommended consumption by participants were zinc, calcium, vitamin A, and vitamin B-6 on both home-delivered meal and non-meal days, and vitamin $C$, folacin, and niacin on non-meal days only. Over half of the participants (59\%) reportedly did not consume the entire home-delivered meal soon after receiving it. However, almost all reportedly were refrigerating the leftover food. Some participants $(41 \%)$ indicated that they would taste or were unsure whether they would taste a food that they suspected "might have gone bad." Some (15\%) would not be concerned or were unsure about eating cooked meat or poultry that had been left at room temperature for more than four hours. Most ( $86 \%$ ) reportedly had been supplied with information about food safety, and most (75\%) did not want any further information. Based on the results, older people at moderate or high nutritional risk need to be identified and ways to reduce such risk need to be developed. Title III-C meals need to increase zinc, calcium, vitamin A, and vitamin B-6 content, and older people need to be educated and encouraged to increase consumption of the above nutrients, as well as vitamin C, folacin, and niacin. More attention should be given to delayed consumption patterns of home-delivered meals, especially concerning food safety practices. 


\section{DEDICATION}

This thesis is dedicated to the memory of my grandfather, Robert Schneider, who inspired my interest in working with this age group. 


\section{ACKNOWLEDGEMENTS}

Thank you to Dr. Lucy Campanis, who served as a member of my thesis committee, and offered some insightful ideas. Thank you to Dr. Martha Brown, who served as a member of my thesis committee, and offered much help with the instrument and the objectives. Thank you to Mike strader, who also served as a member of my thesis committee, and to the Peace Meal staff for all their time and help with the pilot study and the interviews. Thank you to Doug Bower, who helped with the statistics, and offered some very insightful ideas.

A special thank you to Dr. Ruth Dow, my advisor, who believed that I could make this project a success, and dedicated much of her time, effort, help, and guidance. 
TABLE OF CONTENTS

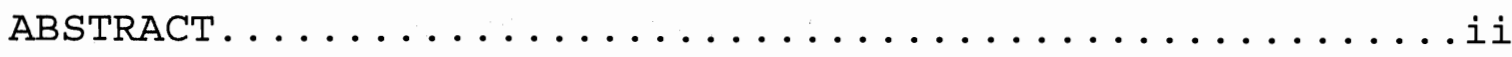

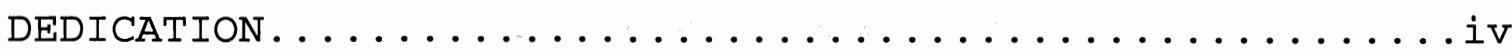

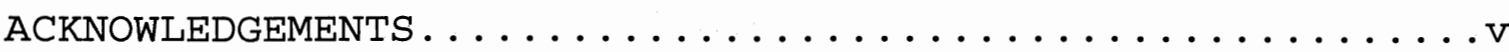

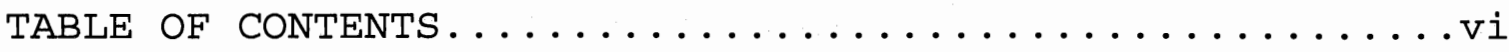

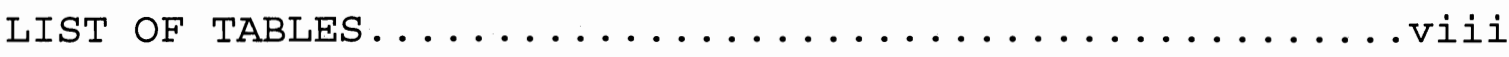

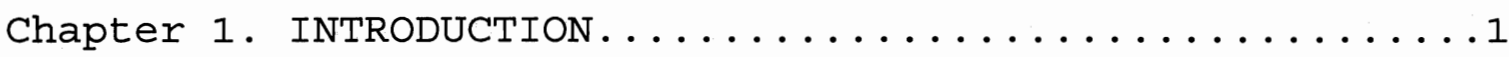

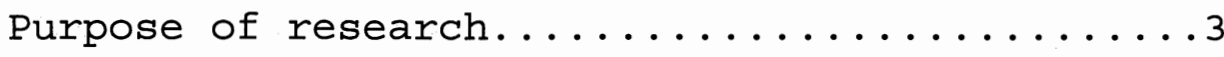

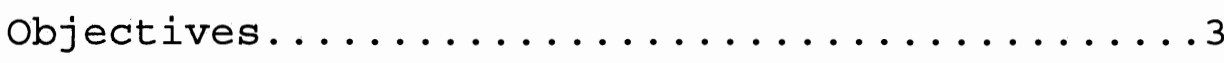

Definition of terms.................

Chapter 2. REVIEW OF LITERATURE................

Recommended Dietary Allowances............

Nutrient needs of older Americans.........6

Nutrient intakes of older Americans........13

Factors affecting consumption...........15

Nutrition programs for older Americans.......19

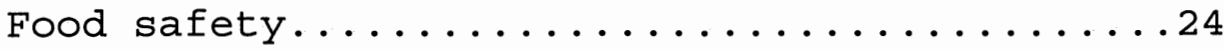

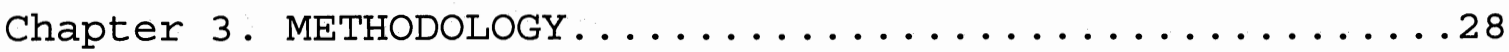

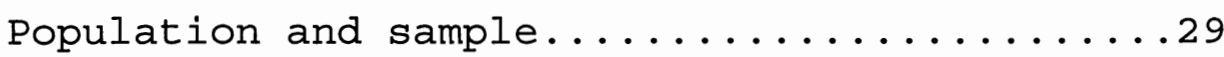

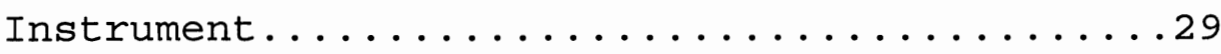

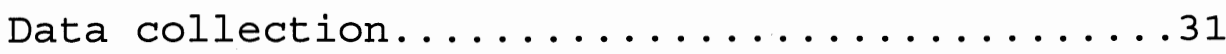

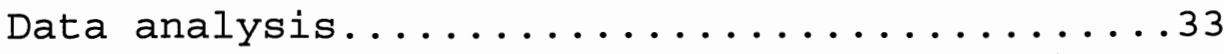

Chapter 4. RESULTS AND DISCUSSION...................

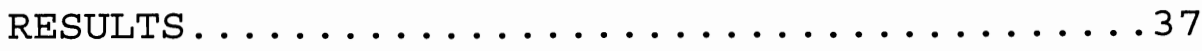

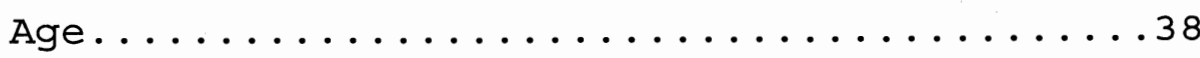

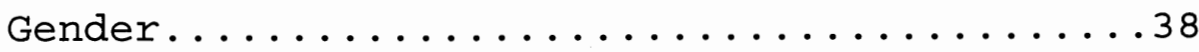


vii

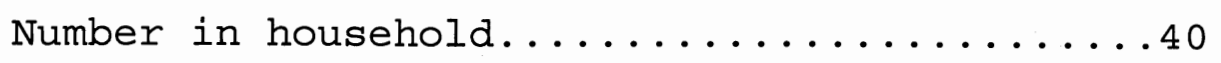

Other meals provided..............40

Diets on home-delivered meal days

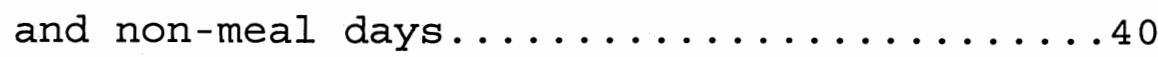

Degree of nutritional risk...........44

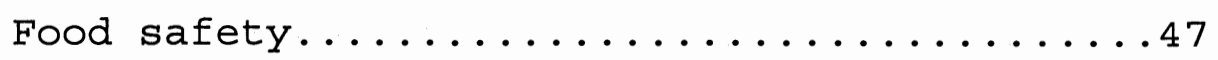

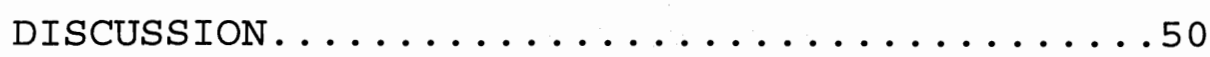

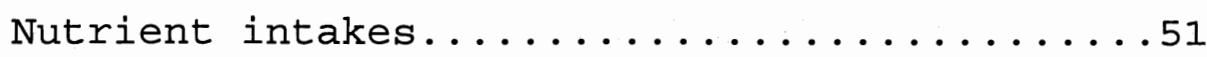

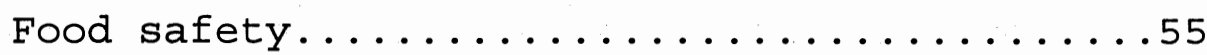

Chapter 5. SUMMARY, CONCLUSION, IMPLICATIONS........59

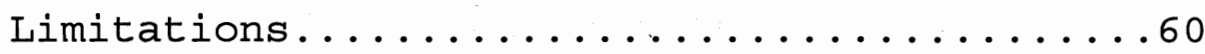

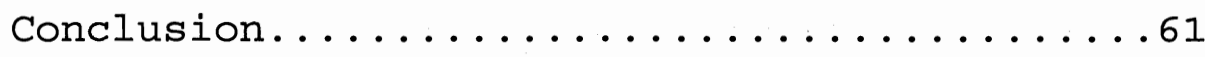

Implications...................62

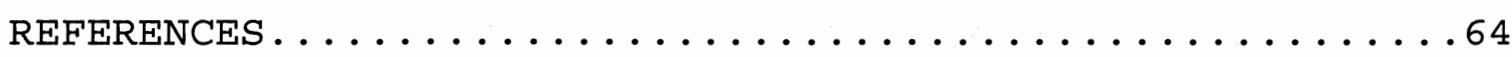

APPENDICES

Appendix A Permission statement...............70

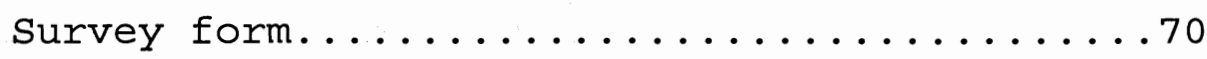

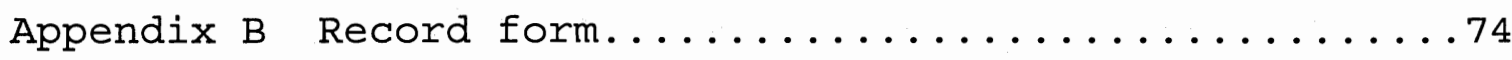




\section{LIST OF TABLES}

TABLE

Mean Nutrient Adequacy Ratios (NARs) by age and gender on home-delivered meal

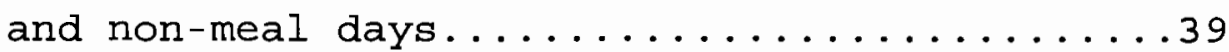
Mean Nutrient Adequacy Ratios (NARs) on home-delivered meal and non-meal days......41 Mean Adequacy Ratios (MARs) on home-delivered meal and non-meal days.................42 Percentage of participants with Nutrient Adequacy Ratios (NARs) on Home-Delivered Meal (HDM) days according to the scale: less than .50, $.50-.66, .67-.99$, and 1.00 and greater...45 Percentage of participants with Nutrient Adequacy Ratios (NARs) on Non-Meal (NM) days according to the scale: less than $.50, .50-.66, .67-.99$, and 1.00 and greater..............46 Percentage of participants at low, moderate, and high nutritional risk on home-delivered meal and non-meal days......48 
CHAPTER 1

INTRODUCTION

The age group known as older Americans represents one of the fastest growing age groups. In fact, those in the age group of 85 years and older are projected to be the fastest growing group of older Americans. According to the United States population reports, older Americans are classified into three subgroups: 1) the young-old - age 65 to 74,2 ) the old-old - age 75-84, and 3) the oldest-old age 85 and older (US Senate Special Committee on Aging America: Trends and Projections, 1988). Many older Americans may be at risk for malnutrition due to one or more factors which may affect food consumption, including loneliness, bereavement, chronic disease, state of health, retirement/leisure time, and limited availability of transportation. In general, these are factors which tend to be more widespread among members of this age group (Schlenker, 1992).

\section{Title III-C (originally Title VII) of the older}

Americans Act was established to provide older persons with low-cost, nutritious meals. Title III-C authorized both congregate and home-delivered meals. Participants of the Title III-C programs must be at least age 60 , although spouses of any age are eligible. Home-delivered meals are transported to homebound older participants (Schlenker, 1992). The Peace Meal program provides both congregate and 
home-delivered meals to older adults in 14 counties in the East Central Illinois area. The Peace Meal program delivers one noon meal, Monday through Friday, to eligible older adults.

Food safety is an important issue in home-delivered meals for a number of reasons, mainly because homedelivered meals require considerable lag-time between production and delivery to the home. Eighty percent of the hot food in this program is delivered in a permanent homedelivered meal tray and recipients are expected to have trays cleaned and ready to be picked up by the homedelivered meal staff the next day. Twenty percent of the hot food is delivered in a hot aluminum foil container. Delivery staff place the trays and the containers on the counter-top in the home; milk is placed in the refrigerator. Thus, if the whole meal is not consumed within a two-hour period (four hours maximum), attention must be given to safe food storage.

Another important issue in home-delivered meals is whether the diets of those receiving these meals meet the 1989 Recommended Dietary Allowances (RDAs) for the age group of older Americans, 51 years and older. Recently, it was estimated that about $16 \%$ of the population 60 years and older are either hungry or malnourished (Burt, 1993). Research has shown that the demand for home-delivered meals has increased (DPG's Collect Data for ADA Testimony, 1985). 
Other research has confirmed that the diets of those receiving home-delivered meals are improved, but still do not meet the RDAs for nutrients studied (Asp \& Darling, 1988; Stevens, Grivetti, \& McDonald, 1992).

\section{Purpose of Research}

The purposes of this study were to assess the diets of Title III-C participants receiving home-delivered meals both on a day of meal delivery and a day of non-meal delivery, and assess the food safety knowledge and practices of the sample.

The objectives for the study were as follows:

1. To compare the diets of participants receiving Home-Delivered Meals to the Recommended Dietary Allowances for the following nutrients: protein, calcium, vitamin A, iron, vitamin C, thiamin, riboflavin, niacin, folacin, vitamin B-6, vitamin B-12, and zinc on a weekday (day of meal delivery) and on a weekend (no meal delivery) based on participants' 24-hour recalls.

2. To compare the dietary intake of participants' weekday diets to weekend diets in comparison to the Recommend Dietary Allowances based on the participants' 24-hour recalls.

3. To examine some food safety practices of participants in relation to Home-Delivered Meals. 
Definition of Terms

For the purpose of clarity, the terms referred to in this study are defined and used as follows:

1. Peace Meal: a program funded under Title III-C of the Older Americans Act. The Peace Meal program covers 14 counties in the East Central Illinois area, and has congregate meal sites and homedelivered meals. Participants must be at least age 60 ; spouses of any age are eligible.

2. Home-Delivered Meals: Peace Meal delivers one noon meal, Monday through Friday, to eligible adults. Recipients must be unable to leave their homes because of a disability or other extenuating circumstances.

3. Recommended Dietary Allowances: U.S. nutrient standards for population groups by age and gender; updated periodically to reflect current research.

4. Twenty-Four Hour Recall: a list of the amounts of all food and beverages reportedly consumed during the previous 24 hours as recalled by the study participants.

5. Food Safety: the means by which food is stored and prepared in order to prevent foodborne illnesses due to microbial food contamination. 
CHAPTER 2

REVIEW OF LITERATURE

The major topics investigated in this review of literature, generally, apply to persons 51 years and older and include the Recommended Dietary Allowances (RDAs), nutrient needs, nutrient intakes, factors affecting food consumption, nutrition programs under the older Americans Act, and food safety concerns.

Recommended Dietary Allowances

The Recommended Dietary Allowances (RDAs) serve as the basis for comparing food consumption to nutrient content. The RDAs were established as a guideline for nutrient needs among different age groups, not for individuals. The most recent RDAs were revised in 1989 (National Research Council, 1989). The RDAs for three nutrients: folic acid, vitamin B-12, and vitamin B-6 were reduced for almost all age and gender groups from the ninth edition of the RDAs (Guthrie, 1990). Even though the RDAs serve as a valuable guideline for maintaining healthy populations, two major limitations of the current RDAs need to be noted, particularly in regard to older Americans.

1) The RDAs apply only to healthy persons. They do not include the special nutritional needs which may arise from chronic diseases, metabolic disorders, injuries, or other medical conditions. 
2) The RDAs which apply to older Americans cover the broad age range of 51 years and older.

The subcommittee for the tenth edition of the RDAs considered subdividing older people into two groups, as increasing age may alter nutritional requirements due to changes in metabolic rate, consumption, absorption, and physical activity. However, the subcommittee concluded that not enough current data existed to establish separate RDAs for people 70 years and older (National Research Council, 1989). Nonetheless, the RDAs have been used as a basis for comparing the nutrient intakes of older Americans (Arnet \& Zahler, 1993; Brown, 1976; Garry, Goodwin, Hunt, Hooper \& Leonard, 1982; Posner, Jette, Smith \& Miller, 1993).

Nutrient Needs of Older Americans

In general, energy requirements are lower in older Americans due to a decrease in physical activity and a lower metabolic rate (Blumberg, 1992; Horwath, 1991). Consumption of total calories tends to be lower in older adults as compared to younger adult Americans. In a study by Wurtman, Lieberman, Tsay, Nader and Chew (1988), persons aged 65-94 consumed, on average, fewer calories than men and women aged 19-33. Even though energy needs usually decrease with age, protein, and most vitamin and mineral needs remain relatively unchanged as people age (Schlenker, 1992). Lower energy requirements may create difficulties in obtaining adequate amounts of required nutrients for older adults. In 
fact, Fischer and Johnson (1990) found that low body weight and rapid unintentional weight loss were significant predictors of mortality and morbidity among those aged 65 and older.

In order to replace nitrogen losses due to dead cells, body secretions, and metabolic end products, sufficient protein must be consumed throughout life, even when physical growth has discontinued. When the diet is protein-poor, nitrogen losses exceed intake, resulting in protein depletion (Schlenker, 1992). The current RDA for protein for men and women aged 51 years and older is $63 \mathrm{~g}$ and $50 \mathrm{~g}$, respectively (National Research Council, 1989).

In a review article, Horwath (1991) stated that dietary supplementation is very widespread in the elderly. According to the review, research showed that $45-70 \%$ of women aged $65+$ and $35-60 \%$ of men aged $65+$ consumed dietary supplements. Nevertheless, vitamin supplements cannot meet all nutrient requirements for an individual. When the American Dietetic Association ( $A D A$ ) testified on the reauthorization of the Older Americans Act, the ADA concluded that the following nutrients should receive attention in regard to meals for older Americans: protein, calcium, vitamin A, iron, vitamin C, thiamin, riboflavin, niacin, folacin, vitamin B-6, vitamin B-12, and zinc (ADA Takes Proactive Stance, Testifies on Older Americans Act Reauthorization, 1984). 
Aging does not necessarily increase the requirement for vitamin A. In fact, vitamin $A$ may be more readily absorbed in older persons (Blumberg, 1992). According to Blumberg (1992), vitamin A allowances for older Americans may need to be lowered. Krasinski, Stradovec, Hartz, Jacob, \& McGandy (1989) compared the vitamin A supplement use of older adults (aged 68-98) and younger adults (aged 19-59). In subjects taking supplements of vitamin A amounting to one to two times the RDA, serum vitamin A levels in older persons were double the levels of younger persons. Currently, the RDA for vitamin A for men and women aged 51+ is $1000 \mathrm{ug} \mathrm{RE}$ and 800 ug RE, respectively (National Research Council, 1989). The RDA for vitamin $\mathrm{C}$ is $60 \mathrm{mg}$, the same as for young adults (National Research Council, 1989). However, according to Vanderjedt, Garry and Bhagavan (1987), ascorbic acid requirements are higher in older men in comparison to older women, because women were shown to maintain higher plasma levels at equal intakes. Jacob, Otradovec, Russell, Munro, Hartz, McGandy, Morrow \& Sadowski (1988) discovered similar results when they assessed the vitamin $C$ status in 677 noninstitutionalized elderly persons aged 60-98. Results confirmed that vitamin $\mathrm{C}$ intake and plasma ascorbic acid levels were higher in females as compared to males. The requirements for thiamin, riboflavin, and niacin are based on energy intake and therefore decrease beyond the 
age of 50 if energy needs decrease (Schlenker, 1992). The 1989 RDA for thiamin in the age group of 51 years and older is $1.2 \mathrm{mg}$ for men and $1.0 \mathrm{mg}$ for women (National Research Council, 1989). The present RDA for riboflavin for men and women aged $51+$ is $1.4 \mathrm{mg}$ and $1.2 \mathrm{mg}$, respectively (National Research Council, 1989). The RDA for niacin for men and women aged $51+$ is $15 \mathrm{mg}$ for men and $13 \mathrm{mg}$ for women (National Research Council, 1989).

The RDAs for folacin, vitamin B-6, and vitamin B-12 were reduced from the ninth to the tenth edition for Americans 51 years and older (National Research Council, 1989; National Research Council, 1980). For folate, the 1989 RDA was reduced to $200 \mathrm{ug}$ for men and $180 \mathrm{ug}$ for women (National Research Council, 1989). Folate deficiency in persons 51 years of age and older is normally associated with poor dietary intake, gastric atrophy, use of medications which may interfere with absorption or utilization, and alcoholism. Usually older persons in hospitals or long-term care facilities are at greatest risk for folate deficiency (Schlenker, 1992).

For vitamin B-6, the 1989 RDA for the age group of $51+$ was reduced from 2.2 to $2.0 \mathrm{mg}$ in men and from 2.0 to $1.6 \mathrm{mg}$ in women (National Research Council, 1989; National Research Council, 1980). Both serum levels of vitamin B-6 and activity levels of red blood cell enzymes requiring vitamin B-6 tend to be lower in older persons in comparison to 
younger persons (Schlenker, 1992). Intake, also, tends to be below recommendations. In one study, $79 \%$ of women and $75 \%$ of men aged 60-96 consumed less than $100 \%$ of the RDA for vitamin B-6 (Manore, Vaughan, Carroll \& Leklem, 1989). Pannemas, van den Berg \& Westerterp (1994) studied the plasma pyridoxal phosphate (PLP) level of 29 young adults (mean age $29+/-1$ ) and 26 elderly (mean age $70+/-1$ ) in response to two varied protein diet regimes: Diet A - $12 \%$ of calories from protein and Diet B - 21\% of calories from protein. It was concluded that plasma PLP was significantly greater during Diet $B$ in elderly subjects in comparison to young adults.

For vitamin B-12, the 1989 RDA for persons 51 years and older was also reduced from $3.0 \mathrm{ug}$ to $2.0 \mathrm{ug}$ in men and 3.0 ug to $1.6 \mathrm{ug}$ in females (National Research Council, 1989; National Research Council, 1980). Serum levels of vitamin B-12 also tend to decrease with advancing age, which may mean that vitamin B-12 is another a nutrient of concern for some older persons (Schlenker, 1992). In a study by Joosten, van den Berg, Riezler, Naurath, Lindenbaum, Stabler \& Allen (1993), 19\% of healthy elderly and $60 \%$ of hospitalized elderly had low serum concentrations of either one or more of the vitamins: B-6, B-12, and folate.

The current RDA for calcium for men and women 51 years+ is $800 \mathrm{mg}$ (National Research Council, 1989). Older women are very vulnerable to osteoporosis, and maintaining 
adequate dietary intakes of calcium throughout life can help prevent osteoporosis. Studies have indicated that higher allowances of calcium around $1500 \mathrm{mg} / \mathrm{d}$ may be needed in order to maintain metabolic balance and /or decrease bone loss in post menopausal women (Consensus Development Conference, 1993; Blumberg, 1992).

The RDA for iron in men and women aged $51+$ is $10 \mathrm{mg}$ (National Research Council, 1989). After the age of 50 in men and after menopause for women, iron stores begin to increase (Schlenker, 1992). However, high iron intake may be of concern to some older persons due to the association between high iron stores and heart disease. Salonen, Nyyssonen, Korpela, Tubmilehto, Seppanen, and Salonen (1992) assessed the association between high serum ferritin concentrations and high dietary intake of iron with the risk of acute myocardial infarction. Results indicated that elevated serum ferritin was a strong risk factor for myocardial infarction. However, Aronow (1993), found no association between increased serum ferritin levels and coronary artery disease in men and women aged $62+$.

zinc is another nutrient which may be of some concern to older persons. For zinc, the current RDA is $15 \mathrm{mg}$ for men and $12 \mathrm{mg}$ for women (National Research Council, 1989). Zinc provides an important role in taste, wound healing, and immune response, which are functions sometimes altered in older persons (Schlenker, 1992). Absorption of zinc is 
not affected as a person ages (Couzy, Kastenmager, Mansourian, Guichar, Munoz-Box \& Dirren, 1993). However, zinc does appear to be a nutrient consumed at lower levels, on average, than the RDA in the diets of older persons. According to Hutton \& Hayes Davis (1993), mean zinc intake was below two-thirds of the RDA in subjects aged $62+$.

The nutrient needs of older Americans merit equal consideration with those of other age groups. Supportive research has shown the following: Energy requirements are lower in older adults; however, protein requirements increase with age. The current RDA for vitamin $A$ is the same for both males and females of all age groups; yet, the current RDA may need to be lowered for older adults. For vitamin $C$, the current RDA for both men and women 51 years and older is the same; yet, men over the age of 51 tend to have lower plasma levels of the vitamin at equal and higher intakes in comparison to women. Serum levels of folate, vitamin B-6, and vitamin B-12 tend to decrease with advancing age. Thus, requirements of these three vitamins may vary in older persons as they age. The RDA for calcium may be lower than is necessary for adults 51 years and older, especially in postmenopausal women due to susceptibility to osteoporosis. High iron stores in older persons may be linked to increased risk for heart disease; however, evidence is not conclusive. Zinc intake remains below recommendation for some older persons in comparison to 
the current RDAs. Overall, there is supportive evidence that the current RDAs may need to be reconsidered and made appropriate for older persons of various age groups. In order to assess extent of risk regarding the nutrient needs of older Americans, it is important to look at their dietary patterns.

Nutrient Intakes of Older Americans

Relatively little is known about the dietary patterns of older Americans, especially among the old-old and the oldest of older Americans (Harris, Woteki, Briefel \& Kleinman, 1989). While not every older American has an inadequate diet in comparison to the current RDAs, many studies have shown that the diets of older adults, in general, need improvement. For example, the Ten state Nutrition Survey of 1968-1970, revealed that the diets of persons 60 years and older, on average, did not meet dietary allowances for protein, iron, and vitamin A (Ten state Nutrition Survey, 1968-1970, 1972). Popkin, Haines \& Patterson (1992) researched trends in eating patterns in older participants, aged 65+, from 1977-78 to 1987-88 and discovered that mean intakes of high-fat beef and pork, whole milk and white bread decreased, while intakes of lowfat beef, pork, poultry and fish, low-fat milk, and wholegrain breads increased. On the contrary, mean intake of high-fat desserts, butter and margarine did not decrease and intakes of fruits, vegetables, and other high fiber foods 
did not increase. Posner et al. (1993) assessed the diets of non-institutionalized older persons, 70 yearst, and found that mean intakes of protein, vitamin $C$, and thiamin met RDA standards for persons 51 years and older. However, 58\% of the sample had nutrient intakes less than $75 \%$ of the RDA for calcium and more than $40 \%$ had intake below $75 \%$ of the RDA for vitamin A. Ryan and Bower (1989) examined the nutrient intake of persons 55 years and older and discovered that 89\% of the sample had poor nutrient intakes for the following nutrients: iron, vitamin B-6, calcium, and vitamin A.

In summary, studies have shown that, in general, dietary intakes tend to be below $100 \%$ of the RDA for the nutrients protein, iron, vitamin A, calcium, vitamin B-6 in older Americans 51 years and older. It is important to note that the dietary patterns of older persons tend to reflect lifelong attitudes and habits, which are influenced by the environment. Thus, many influencing factors may contribute to the dietary patterns of older Americans (Schlenker, 1992). Various disease states and nutrient intake both affect nutritional status in individuals. Factors affecting consumption will be further discussed in this review of literature, but various disease states will not be further discussed. 
Factors Affecting Consumption

Many older Americans experience various psychological, physiological, and socioeconomic factors which may affect food consumption. Some of these factors include loneliness, social isolation, decreased mental awareness, loss of appetite, loss of taste, chronic disease, limited transportation, and limited income, which tend to be factors more prevalent among older Americans. These factors may affect the quantity and/or quality of food ingested, thus placing some older Americans at nutritional risk (Schlenker, 1992).

Two potential psychological factors which may influence poor nutrition are living alone and social isolation. In this society, eating is often a social activity. Food is usually consumed with friends, companions, and family members. However, children moving away and the loss of a spouse or friends may result in living alone and the loss of eating companions. Several of the following studies have assessed the relationship between living alone and nutrient intake. Davis, Murphy, and Nehaus (1988) analyzed the eating behaviors of persons aged 55 years and older in relationship to living arrangements. Nineteen percent of men living alone reported meal skipping, while only $10 \%$ of men living with a spouse reported meal skipping. For women, 12\% living alone reported meal skipping, while $10.5 \%$ of women living with a spouse reported 
meal skipping. Eighty-four percent of men and $86 \%$ of women living alone ate alone. Zipp and Holcolmb (1992) found that elderly women living alone and those with a spouse had mean nutrient intakes which were above $75 \%$ of the RDA for all nutrients except energy. The elderly women living alone actually had slightly higher mean intakes for calcium and riboflavin in comparison to women living with a spouse. In a study by Davis, Murphy and Lein (1990), 25\% of men living alone, aged 75+, and 22\% of women living alone, aged 55-64, had three-day dietary intakes which were less than twothirds of the RDAs for five or more nutrients. In a study by DeCastro and DeCastro (1989), older Americans eating alone consumed, on average, 51 fewer calories from carbohydrates, 73 fewer calories from fat, and 35 fewer calories from protein per one meal than older Americans eating with one or more companions. McIntosh, Shifflet, and Picou (1989) reported that persons 65 years and older with a more extensive network of companions had higher mean intakes of protein, calories, and vitamins and minerals compared to those without such networks.

Numerous physiological changes which occur by the time an individual reaches the age of 60 , may include sensory loss, dental problems, and impaired physical health. These changes may affect food selection, consumption, and utilization by the body. Medications and alcohol intake may affect the ingestion, absorption, utilization, and/or 
excretion of nutrients. Many chronic diseases associated with aging are managed with prescription drugs. Older people often use multiple prescriptions and over the counter medications, which may affect nutritional status (Schlenker, 1992).

As a person ages, tolerance to alcohol decreases and adverse side effects increase. Alcohol intake may lead to lower food intake, and kilocalories from alcohol may replace carbohydrates, fat, and protein. Alcohol may also interfere with absorption of vitamin B-12 and folate, and excessive zinc excretion is associated with alcohol abuse (Schlenker, 1992).

Spitzer (1988) reported that diminished taste and olfactory acuity may lead to poor nutrition. In a study by Gordon, Kelly, Sybyl, Mill, Kramer, and Jahnigen (1985), individuals with dentures had significantly better overall nutritional status than older individuals with toothlessness or poor natural dentition.

Possible socioeconomic barriers such as inadequate financial resources, retirement, and aging may lead to poorer eating habits and nutritional intake among older adults. In a study by Davis, Randall, Forthhofer, Lee, and Magen (1985), level of income was one factor associated with the consumption of less than two-thirds $(67 \%)$ of the RDA for at least five of the eight nutrients studied. Thirty-six percent of the men and $31.3 \%$ of the women with an income 
below poverty level and who lived alone consumed less than 67\% of the RDAs for five of eight nutrients. Arnet and Zahler (1993) looked at the dietary intakes of healthy retired elderly men and found that $21 \%$ consumed less than 67\% of the RDAs for calcium and vitamin C.

Gender also was one factor which was shown to have a significant affect on nutrient intake among older people. Hatangady-Mahajan and Scafer (1993) reviewed the association between gender, marital status and of dietary intake in noninstitutionalized elderly aged 65+. Nutrient density calculations revealed that potassium, carbohydrates, and vitamin C were significantly higher for females, while intakes of phosphorus, iron, calcium, thiamin, riboflavin, and niacin were significantly higher for males. Single older men, on average, consumed 1906 calories per day, and married older men, on average, consumed 1860 calories. Likewise, single older females consumed, on average, 1649 calories per day and married older females consumed 1484 calories per day.

In the above studies, living alone, diminished sensory acuity, and low income affected nutrient intake of a significant number of people. Because these factors tend to be more prevalent in older adults, the need for nutrition programs for older Americans is evident. 
Nutrition Programs for Older Americans

Title III-C of the Older Americans Act of 1965 was established to provide older Americans with low-cost nutritious meals, nutrition education, and an opportunity for social interaction (Schlenker, 1992). The legislation for Title VII (eventually changed to Title III-C) specified four reasons for such a program: a) lower incomes and poverty among elderly may make the affordability of an adequate diet difficult, b) malnutrition among minority elderly is very prevalent, c) many older people experience isolation and loneliness which may hinder proper nutrition, and d) decreased mobility prevalent among the elderly may create difficulties in shopping for food (Wells, 1973).

Title III-C established two nutrition programs, Congregate Meals and Home-delivered Meals programs, which were designed to serve those who are 60 years and older (spouses of any age may also be included). The only eligibility is age (Schlenker, 1992). However, meals provided by Title III-C funds must comply with the Dietary Guidelines for Americans and provide at least one-third $(33 \%)$ of the RDAs if one meal per day is served (older Americans Act Passes, 1992).

Considerable evidence has shown that the diets of older persons benefit on the day a congregate meal is served. In a study by Kohrs, O'Hanlon, and Ecklund (1978), trained interviewers collected one-day food records from 
participants and a control group and analyzed nutrient intakes. Results showed that individuals who consumed the program meal on the day of food record collection had a higher percentage of the RDAs for energy, protein, calcium, riboflavin, and niacin. Dow (1977) conducted a three-day dietary survey of congregate meal participants and found that $40 \%$ had diets which met two-thirds or more $(67 \%+)$ of the RDAs. Brown (1979) compared the dietary intakes of part-time congregate meal participants, regular congregate meal participants, non-congregate meal participants, and recipients of home supportive services. Diets were rated on the basis of excellent (all nutrients meeting $100 \%+$ of the RDA), good (all nutrients meeting at least $67 \%$ of the RDA), fair (all nutrients meeting at least $50 \%$ of the RDA), poor (any one nutrient below 50\% of the RDA). In addition, a nutrient score between 0 and 8 was determined. A nutrient score of eight represented the highest score and meant that the subject met at least $67 \%$ of the RDA for all eight nutrients. Regular participants in the congregate meals program had a mean nutrient score of 7.74 representing the highest, while, recipients of home supportive services had the lowest mean nutrient intake score of 6.00 . Seventy percent of the regular congregate meal participants, $52 \%$ of the part-time participants, $46 \%$ of the non-participants and $44 \%$ of the home supportive services group had diet, which were classified as good. 
In the above studies, at least $40 \%$ of the older Americans attending congregate meal sites had diets which met at least $67 \%$ of the RDA for all nutrients. Older adults attending congregate meals have the advantage of being mobile and enjoying social interaction. On the other hand, homebound older individuals may or may not live alone, may have limited mobility, limited social interaction, and a debilitating disease or illness which may hinder Congregate Meal participation. Thus, legislation for the older Americans Act also recognized the need for home-delivered meals.

Homebound elderly are faced with even greater factors which may affect food consumption. To be eligible to receive a home-delivered meal through the Title III-C program, participants must be 60 years and older, and must be unable to leave the home due to disability or other extenuating circumstances. Recipients of home-delivered meals may be referred by a family member, physician, visiting nurse, dietitian, outreach worker, or social worker (Schlenker, 1992). Posner, Smiegelski, McLaren, and Krachfels (1987) examined the food and nutrient needs of homebound persons with a mean age of 82 . According to the results, $30 \%$ had incomes below poverty level. Mean calcium, energy, and folic acid intakes were below the RDAs for both men and women. 
The implementation of the Diagnosis Related Groups (DRGs) has resulted in earlier patient discharge from medical facilities. A diagnosis-related group is defined as a US government cost-containment management classification scheme for predesignation of Medicare payments based on specific diagnosis categories of disease (Schlenker, 1992). The DRG's have led to an increase in the need for homedelivered meals. Recently, the $\mathrm{ADA}$ collected data regarding the impact of the DRG's on home-delivered meals. Results from three states, Washington, Florida, and Kansas, exhibited 35-57\% increases in demand for home-delivered meals after the DRG's were established. Washington had an $168 \%$ increase in demand for therapeutic diets, with $44 \%$ of the clients being early releases (DPG's Collect Data for ADA Testimony: Effect of DRG's on Demand for Home-Delivered meals, 1985).

It can be argued that if home-delivered meals were not provided to clientele, more expensive services in long-term care facilities would be necessary. Edward, Frongillo, Rauschenbach, and Roe (1993) studied the effects of the home-delivered meal program on the control of diabetes in a diabetic sample. Results showed that $52 \%$ of the group not receiving home-delivered meals were diagnosed with uncontrolled diabetes mellitus and $22 \%$ were hospitalized because of it, but $38 \%$ of those receiving home-delivered meals were diagnosed with uncontrolled diabetes mellitus and 
7\% were hospitalized because of it.

According to Asp and Darling (1988) the diets of older Americans receiving home-delivered meals remain, on average, inadequate when compared to the RDAs. They assessed whether home-delivered meals met the RDAs and whether the diets of recipients were improved. Meals were studied each year for five consecutive days during a six-year period. In each year studied, meals did not always meet serving size guidelines. Milk was not delivered with meals. In each year studied, the calcium provided was less than $33 \%$ of the RDA. Energy and thiamin were also provided at less than $33 \%$ of the RDA for men, and riboflavin and vitamin $C$ were provided at less than 33\% of the RDA for both men and women for one or more years. Twenty-four hour dietary intakes were also assessed. More than $50 \%$ of the 22 participants had daily calcium intakes less than $67 \%$ of the RDAs. Between $20 \%$ to $40 \%$ of the sample had one-day intakes of vitamin C, thiamin, riboflavin, and energy which were less than $67 \%$ of the RDA. Stevens, Grivetti \& McDonald (1992) evaluated the nutrient intake of both rural and urban homebound older American clients in the Title III-C meal program. Each participant met or exceeded $100 \%$ of the RDA for all nutrients other than energy, vitamin B-6, calcium, magnesium, and zinc. However, 70\% had intakes which were below $67 \%$ of the RDA for three or more nutrients and were classified as having poor diets. 
Clearly, the implementation of the DRG's in combination with the growing population of older Americans is creating an increase in the demand for home-delivered meals. The above studies have shown that the diets of homebound older people need improvement, even on days of meal delivery. Mean dietary intake of calcium, energy, folic acid, thiamin, riboflavin, and vitamin C still remain below the RDAs. Even so, considerable evidence has shown that receiving one nutritious meal per day does contribute to the improvement of the diets of homebound older Americans, and may help reduce hospitalizations. However, the demand for homedelivered meals exceeds the supply due to budget constraints (Burt, 1993). Some providers of home-delivered meals are electing to offer supplementary frozen meals. Frozen meals may have the advantages of cutting waste and cost, and increasing microbiological control. As susceptibility to foodborne illnesses is a major concern among the elderly, food safety is a major issue related to home-delivered meals (Thole, Gregoire, 1992).

\section{Food Safety}

Any food containing $\mathrm{milk} / \mathrm{milk}$ products, eggs, meat, poultry, fish, shellfish, and/or edible crustacea is potentially hazardous. Foods most commonly reported as causing foodborne illness include dairy products, custards, meats, protein salads and eggs (Brown, 1986). Foodborne illness becomes a problem when potentially hazardous foods 
are poorly stored due to prolonged holding of cooked food in warm places, inadequate refrigeration, and insufficient heating. A safe temperature to store potentially hazardous leftovers is 40 degrees $F$ or below (West \& Wood, 1988). Black and Lewis (1948) conducted a study in which varying cooling rates of protein foods were observed. All foods were divided into equal portions, placed in similar containers, cooled at room temperature for various intervals of time, and refrigerated. In general, prompt chilling most effectively retarded bacterial multiplication. As elderly people have a high susceptibility to food borne illness (Doyle, 1993; Bauman, 1974), food safety and sanitation are important factors to consider in both congregate and homedelivered meals. Since home-delivered meals require a longer period between food production and delivery to the home, safety and sanitation are even more crucial than for congregate meals. Asp et al. (1988) examined the temperatures of home-delivered meals at the point of arrival. Temperature ranges were as follows: 86-140 degrees $F$ for meat, 90-153 degrees $F$ for potatoes, and 77140 degrees $F$ for vegetables in the seven years that the meals were studied.

Home food preparation practices are another area of concern, particularly since the incidence of foodborne disease is on the rise, mainly due to food mishandling (West \& Wood, 1988). Williamson, Gravani, and Lawless (1992) 
examined consumer knowledge of key home food-safety terms and concepts, information on consumer home-food preparation practices, and whether consumer food-safety knowledge could be correlated with proper home food-preparation practices. Seventy-five percent of the respondents knew that salmonella was associated with raw poultry and eggs. Eighty-five percent reported that they would not taste a suspected food to determine food safety, and $18 \%$ said they would not be concerned or were not sure about cooked meat being left out at room temperature for more than four hours.

In summary, many studies have evaluated the diets of older Americans in comparison to the Recommended Dietary Allowances (RDAs) for men and women aged 51 years and older. The age group of $51+$ is extremely broad and does not take into consideration the possibility that the nutrient needs of people aged 51 may be quite different than the nutrient needs of people who are 70 years old and beyond. As an adult ages, metabolism declines, yet the risk of disease and illness increases.

Some older Americans contend with many psychological, physiological, and socioeconomic factors which may affect the way they consume food, and may increase their nutritional risk. Title III-C of the Older Americans Act was established to provide adults 60 years and older with low-cost, nutritious meals. Title III-C established both the Congregate and Home-Delivered Meals. These meals must 
comply with at least $33 \%$ of the RDA for men and women 51 years and older if one meal per day is served.

Homebound older Americans are faced with even greater physiological, psychological, and socioeconomic factors which may affect the way food is consumed. In general, studies have shown that participants receiving congregate meals have improved diets. However, the diets of those receiving Home-Delivered Meals are usually less adequate in comparison to the RDAs. Although few studies of the diets of adults receiving home-delivered meals exist, homedelivered meals provide beneficiaries with at least onethird of the RDAs on the days that a meal is served. However, more research is needed to assess the diets of individuals receiving home-delivered meals. Older Americans are susceptible to foodborne illness. Food safety practices are of great concern among this age group, particularly in the area of storage practices, since some recipients of home-delivered meals may not be consuming $100 \%$ of the meal within a safe time period. 


\section{CHAPTER 3}

\section{METHODOLOGY}

The purposes of this research were to assess the diets of those receiving home-delivered meals, both on a day of meal delivery and a day of no meal delivery, and some food safety practices of the sample. Specific objectives were (1) to compare the diets of participants receiving homedelivered meals to the RDAs for the following nutrients: protein, calcium, vitamin A, iron, vitamin C, thiamin, riboflavin, niacin, folacin, vitamin B-6, vitamin B-12, and zinc on a week day (day of meal delivery) and on a weekend (day of no meal delivery) based on the participants' 24-hour recalls; (2) to compare the dietary intakes of participants' weekday diets to weekend diets in comparison to the RDAs based on participants' 24-hour recalls; (3) to examine some food safety practices of participants in relation to home delivered meals. The above nutrients were identified by the American Dietetic Association as needing to receive attention in regard to meals for older Americans (ADA Takes Proactive Stance, Testifies on Older Americans Act Reauthorization, 1984). Data were collected via homeinterviews with the assistance of a multi-part questionnaire to be used on two different days (Appendix A). All answers were recorded on a separate form designed to assist the interviewers in recording the answers (Appendix B). 
Population and Sample

Approximately 600 older adults of all socioeconomic classes receive home-delivered meals through the Peace Meal program. About $30 \%$ have incomes considered to be below the poverty level. In order to qualify in this study, individuals had to be (1) receiving Peace Meal homedelivered meals on a long-term basis; (2) considered by the Peace Meal staff to be lucid and able to respond to interviewers' questions. Experts in the fields of nutrition and dietetics and gerontology agreed that a random sample of about 125 people, meeting the above qualifications, should be selected to obtain at least a final sample of 100 program participants. Those qualifying for the study were asked ahead of time, either via a phone call or person-to-person visit, whether they would or would not agree to participate in the study (Appendix A). Twenty-four individuals either declined to give consent or were unavailable for an interview. A total of 101 participants agreed to answer questions via home interviews on two separate days (a day of meal delivery and a day of no meal delivery). The sample came from both rural and urban areas in the five East Central Illinois counties of McLean, Champaign, Coles, Cumberland, and Douglas.

Instrument

A questionnaire to be used on two different days was designed with 16 items in four sections (Appendix A): The 
first section consisted of questions asked only on the first day, designed to obtain general information: height, weight, vitamin and mineral supplementation, whether other meals are provided, whether participant cooks for self, and whether participant has refrigerator, freezer, and range. Section two consisted of questions to be asked at both visits, and was designed to obtain information about the diets of participants on a home-delivered meal (HDM) day and a nonmeal (NM) day via use of the 24-hour recall. Section three consisted of questions to be asked the day after a HDM day, and was designed to obtain information on actual HDM food safety practices. The fourth section consisted of questions to be asked only during the first visit, and was designed to obtain limited information on food safety practices. The record sheet (Appendix B) was designed so that answers from the questionnaires could be recorded on the form. Items on the record sheet were numbered to correspond with the items on the questionnaire (Appendix A). Other information recorded on the form included demographic information. Also recorded was the home-delivered menu: usually entree (protein), vegetable 1 , vegetable 2 (some days), fruit (some days, depending on the dessert), bread, margarine (not supplied at all congregate meal sites), dessert (depending on whether a fruit was served), and milk. The record forms were color-coded. A yellow form was used for the day after the HDM. A white form was used for the day after the NM. 
Data Collection

This study was a follow-up to the study conducted by Dow (1977). The purpose of her study was to assess the extent to which the diets of participants attending congregate meal sites in East Central Illinois met the 1974 RDAs for adults, 51 years and older, for the nutrients: protein, calcium, iron, thiamin, riboflavin, niacin, vitamin A, and ascorbic acid. The diets were rated as follows: $\% \mathrm{RDA}$ for one or more nutrients

$\begin{array}{lc}\text { Poor } & \text { Less than } 50 \\ \text { Fair } & 50-66 \\ \text { Good } & 67-99 \\ \text { Excellent } & 100+\end{array}$

The questionnaire used for the present study was revised from the questionnaire used by Dow (1977). Questions were added to assess some food safety practices. Additional questions were developed with the assistance of a professor in nutrition and dietetics at Eastern Illinois University. To establish validity, the revised questionnaire and accompanying record sheet were approved by the following specialists: three professors in nutrition and dietetics, a professor with a background in research methods, the director of the Peace Meal Senior Nutrition Program in Charleston, Illinois, and four other Peace Meal 
staff. Additional changes were made to the questionnaire based on their suggestions.

In order to establish reliability, a pilot test was conducted. Nine adults receiving home-delivered meals (HDMs), from Coles and Cumberland counties, were interviewed in their homes. Two questions were revised in order to clarify terminology. Interviewers were the researcher and four Peace Meal staff: 1) HDM Coordinator/Outreach, Region I, 2) HDM Coordinator/Outreach, Region II, 3) HDM Coordinator/Outreach, Region III, and 4) HDM Coordinator/Outreach, Region III. To ensure that initial and probing questions would be consistent, the researcher held a training session for the five interviewers. The interviewers were carefully coached how to ask and record information consistently. They practiced mock interviews with a Peace Meal worker who was not an interviewer.

In order to establish exact portion size of foods consumed, food models were distributed to the interviewers to be used to assist in the 24-hour recalls (Karvetti \& Knuts, 1985; Madden, Goodman, \& Guthrie, 1976). The food models consisted of measuring cups and spoons, clay food models representing one-half portions of starches, salads, soups, desserts, and vegetables, and a deck of cards to represent three ounces of meat. Also, the interviewers were instructed to ask probing questions - How many? How was this prepared? What was in that food? Did you have 
anything on your hamburger/sandwich? Did you have anything in your coffee? Recipes for standard portion sizes were obtained for the following Peace Meal foods: Settler's Beef \& Beans, Sunshine Salad, Layered Lettuce Salad, Gelatin w/ Fruit, and Beef Roll.

Interviewers went into the homes of the participants for two visits. As meals were delivered Monday through Friday, one visit was on a random day Tuesday through Friday to complete sections two and three of the questionnaire (Appendices A\& B), for a HDM day. Another visit was made only on Mondays to complete section two (Appendices A\& B), for a NM day. Sections one and four were completed on the first visit (Appendices $A \& B$ ). All interviews were conducted within a two-month period in late 1994. Each interview was approximately 20 minutes in length. Fiftyeight first visits were made on a Monday (day after a NM). Forty-three first visits were made on a random day Tuesday through Friday (day after a HDM). In addition, the Peace Meal staff interviewers were asked to recall whether they may have observed any food safety problems during routine home assessments. One specific concern was clientele not refrigerating unconsumed leftover food that has the potential to cause foodborne illness from the delivered meals. This was done for the purpose of targeting potential food safety problems of recipients not in the study. 
Data Analysis

Foods and amounts consumed, from the 24-hour recalls, were entered into the Nutritionist III, volume 4 (1988), computer software and may be used on any IBM compatible or Apple McIntosh computers. The Nutritionist III analyzed the foods and produced an overall daily total of RDA percentages for each nutrient as compared to the 1989 Recommended Dietary Allowances. The Nutritionist III has the capability of analyzing 58 nutrients for over 1900 foods. All foods were entered directly by name; therefore, no coding was necessary. In this software, data were complete for all twelve nutrients selected.

Degree of nutrient risk for each individual was assessed, first by calculating a Nutrient Adequacy Ratio (NAR) for 12 nutrients: protein, calcium, vitamin A, iron, vitamin C, thiamin, riboflavin, niacin, vitamin B-6, vitamin B-12, folacin, and zinc, by using the following equation (Krebs-Smith \& Clark, 1989; Guthrie \& Scheer, 1981): NAR = subject's average daily intake of a nutrient age- and sex-specific RDA for that nutrient The nutrients listed were identified by the American Dietetic Association as needing special attention in the diets of older persons (ADA Takes Proactive stance, Testifies on the Older Americans Act Reauthorization, 1984). NARs were not allowed to exceed 1.00 , even if the participant consumed greater than the RDA for a nutrient 
because, according to Krebs-Smith \& Clark (1989), there is no apparent nutritional advantage to obtaining more than the RDA of any nutrient.

Next, a Mean Adequacy Ratio (MAR) was determined for each participant (Krebs-Smith \& Clark, 1989; Guthrie \& Scheer, 1981):

$$
\begin{aligned}
\text { MAR }= & \text { sum of the NARs for selected nutrients } \\
& \text { number of nutrients being assessed (12 } \\
& \text { in this study) }
\end{aligned}
$$

Participants were classified as being at low risk, moderate risk, and high nutritional risk according to the following scale:

$\begin{array}{lcl}\text { MAR } & >.66 & \text { Low Nutritional Risk } \\ \text { MAR } & .50-.66 & \text { Moderate Nutritional Risk } \\ \text { MAR } & <.50 & \text { High Nutritional Risk }\end{array}$

Many studies have used $67 \%$ of the Recommended Dietary Allowance as a cut-off value when examining the adequacy of diets for elderly populations (Ryan \& Bower, 1989; Davis et al., 1990; Davis et al., 1985). Other studies have used categories to classify nutrient intakes as excellent, good, fair, or poor (Kohrs et al., 1978; Brown, 1979; Dow, 1977; Brown, 1976).

In addition, a scale was determined for the purpose of viewing the participants' dietary intake of each of the twelve nutrients. A percentage was determined for participants with NARs above 1.00, NARs between .67-.99, 
NARs between .50-.66, and NARs below .50, for each of the 12 nutrients. However, no classification was given to nutrient intakes falling in each of the four categories.

The SPSS statistical package (1994) was used to analyze dietary and survey information. Valid percentages were calculated from responses to the 16-item questionnaire (Appendices $A \& B$ ). The relationship between age and NARs and MARs on both HDM and NM days was analyzed by Pearson Product Moment. Age was divided into three categories: 65-74, (2) 75-84, (3) $85+$ (US Senate Special Committee on Aging, 1988). A t-test was used to analyze the relationship between gender, number in household, and other meals provided with NARs and MARs on both HDM and NM days. Also, significance of NARs and MARs for the 12 nutrients was analyzed by t-test. Cross tabulations were run for age, gender, and age with gender to assess degree of nutritional risk on HDM and NM days. Significance was established at $\underline{p}$ $<.05$. 
CHAPTER 4

$\underline{\text { Results }}$

\section{RESULTS AND DISCUSSION}

The objectives of this study were to compare the diets of participants receiving HDM to the RDAs for 12 nutrients on a weekday (day of meal delivery) to a weekend day (day of no meal delivery) based on 24-hour recalls; to compare intakes of weekday diets to weekend diets based on 24-hour recalls; and to examine some food safety practices in relation to home-delivered meals. Data from a total of 101 participants were collected and analyzed.

The major findings of the study were as follows: On a home-delivered meal (HDM) day, the diets of recipients more closely met the RDAs for adults 51 years and older in comparison to a day with no meal (NM) delivery. Mean intakes indicated that most participants were at low nutritional risk on both $\mathrm{HDM}$ and NM days. Individual nutrients identified as of concern due to less than recommended consumption by participants were zinc, calcium, vitamin A, and vitamin B-6 on both HDM and NM days, and vitamin C, folacin, and niacin on NM days only. Over half of the participants reportedly did not consume the entire home-delivered meal soon after receipt, but almost all reportedly were refrigerating the leftover food. Some participants indicated that they would taste or were unsure whether they would taste a food they suspected "might have gone bad." 
Some would not be concerned or were unsure about eating cooked meat or poultry that had been left at room temperature for more than four hours. Most reportedly had been supplied with information on food safety, and most did not want any further information.

Age. The mean age of the participants was 79 (n=95). Six participants chose not to reveal age. Ages of the participants ranged from 51-99 (Only one participant was below the age of 60 , and qualified to receive a meal, because his spouse was above age 60.) Age categories were (1) $65-74$, (2) $75-84$, and (3) $85+$, categories used by the US Senate Special Committee on Aging (1988). Age was not significantly correlated with Nutrient Adequacy Ratios (NARs) or Mean Adequacy Ratios (MARs) on either HDM or NM days

Gender. Sixty-nine percent of the sample were female. Men had significantly higher NARs for niacin and iron in comparison to women, but only on HDM days. Table 1 shows the mean NARs for the three age groups and both genders on HDM and NM days. The mean Nutrient Adequacy Ratios (NARs) are the mean intake of each nutrient. The Mean Adequacy Ratio is the sum of the NARs of the 12 nutrients divided by the number 12 .

Number in household. Seventy percent of the sample lived alone. Twenty-eight percent lived with more than two people. There was no significant correlation between living 
Table 1

Mean Nutrient Adequacy Ratios (NARS) by Age and Gender on Home-Delivered Meal (HDM) and Non-Meal (NM) days

Age

Gender

$n * \quad 65-74$

$n *$

$75-84$

$n * 85+$

\begin{tabular}{|c|c|c|c|c|c|c|}
\hline & & & $\mathrm{HD}$ & & & \\
\hline Female & 21 & .8853 & 20 & .8595 & 24 & .8439 \\
\hline \multirow[t]{2}{*}{ Male } & 11 & .8389 & 14 & .9236 & 5 & .8955 \\
\hline & & & \multicolumn{4}{|l|}{ NM } \\
\hline Female & 21 & .8400 & 20 & .7606 & 24 & .8159 \\
\hline Male & 11 & .7679 & 14 & .7951 & 5 & .8095 \\
\hline
\end{tabular}

Note. Maximum NAR $=1.00$.

* Six participants did reveal their age. 
arrangement and NARs and MARs on either HDM or NM days.

Other meals provided. Sixty percent reportedly

received meals in addition to the HDM from friends, family, neighbors, or other agencies. There was no significant correlation between receiving other meals and NARs and MARs on either HDM or NM days.

Diets on home-delivered meal days and non-meal days. The dietary intakes of the sample on HDM days more closely met the RDAs for the following nutrients: protein, calcium, vitamin A, iron, vitamin C, thiamin, riboflavin, niacin, folacin, and vitamin B-12, in comparison to the dietary intakes on NM days (Table 2$)(\underline{p}<.05$ and .01). The mean NAR for protein was highest at .9448 on HDM days, and the mean NAR for riboflavin was highest on NM days at .8969. The maximum NAR possible was 1.00 , because there is no apparent nutritional advantage to obtaining more than the RDA of any nutrient (Krebs-Smith \& Clark, 1989). The mean NARs of zinc were the lowest on both HDM and NM days at .6223 and .5769 , respectively. The greatest numerical difference between mean NARs of a nutrient was evident for calcium in which mean NAR was .8095 on HDM days and .6922 on NM days. The Mean Adequacy Ratio (MARs), which is the sum of the NARs of the 12 nutrients divided by the number 12, were significantly higher on HDM days in comparison to NM days $(\underline{p}<.01)$. Table 3 shows this relationship. As far as individual nutrient intakes on HDM days is concerned, $81 \%$ of 
Table 2

Mean Nutrient Adequacy Ratios (NARs) on Home-Delivered Meal (HDM) and Non-Meal (NM) Days

Meal

Nutrient

HDM

NM

\begin{tabular}{lcc}
\hline Protein & $.9448 * *$ & .8921 \\
Calcium & $.8095 * *$ & .6922 \\
Vitamin A & $.8018 *$ & .7275 \\
Iron & $.9100 * *$ & .8516 \\
Vitamin C & $.9105 * *$ & .8309 \\
Thiamin & $.9424 * *$ & .8759 \\
Ribofilavin & $.9513 * *$ & .8969 \\
Niacin & $.9157 *$ & .8678 \\
Folacin & $.8534 * *$ & .7637 \\
Vitamin B-6 & .7508 & .7078 \\
Vitamin B-12 & $.9350 * *$ & .8592 \\
Zinc & .6233 & .5769 \\
\hline
\end{tabular}

Note. Maximum NAR $=1.00$.

$* \underline{p}<.05 . * * \underline{p}<.01$. 
Table 3

Mean Adequacy Ratios (MARs) on Home-Delivered Meal (HDM) and Non-Meal (NM) Days.

MAR

Day

HDM

.8624 *

NM

.7952

Note. Maximum $\mathrm{MAR}=1.00$.

$* \underline{p}<.01$. 
the participants had NARs either equal to or greater than 1.00 for the nutrient riboflavin, which was the highest NAR for any nutrient. Thirty-six percent had NARs less than .50 for the nutrient zinc, which was the highest percentage in the category of less than .50. Only 33\% had NARs between $.67-.99$, and $10 \%$ had NARs at 1.00 or greater for zinc. Other noteworthy nutrients on HDM days were calcium, vitamin A, and vitamin B-6. Fourteen percent of the sample had NARs less than .50 for calcium, while 33\% had NARs between .67 .99 , and $39 \%$ had NARs at 1.00 or greater for calcium. Sixteen percent had NARs less than .50 for vitamin A, while 23\% had NARs between .67 - .99, and 49\% had NARs at 1.00 or greater for vitamin A. Twenty-one percent had NARs less than .50 for vitamin B-6, while 26\% had NARs between $.67-$ .99 , and $34 \%$ had NARs at 1.00 or greater. Individual nutrient intakes on NM days showed that $66 \%$ of the participants had NARs at 1.00 or greater for the nutrient riboflavin. Thirty-seven percent had NARs less than .50 for the nutrient zinc, which was the highest percentage for any nutrient intake less than .50 . Only $18 \%$ had NARs between $.67-.99$, and $13 \%$ had NARs at 1.00 or greater for zinc. Other nutrients of note are calcium, vitamin A, vitamin C, niacin, folacin, and vitamin B-6. More than ten percent of the participants had NARs less than .50 for calcium, vitamin A, vitamin C, niacin, folacin, and vitamin $B-6$. 
Table 4 shows the percentage of participants with Nutrient Adequacy Ratios (NARs) on HDM days according to the scale: less than $.50, .50-.66, .67-.99$, and 1.00 and greater. Table 5 shows the percentage of participants with Nutrient Adequacy Ratios (NARs) on NM days according to the scale: less than $.50, .50-.66, .67-.99$, and 1.00 and greater. It is worth noting that the percentages of participants with nutrient intake less than .50 is lower for all nutrients on HDM days in comparison to NM days. Also, the percentages of participants with nutrient intakes at 1.00 or greater is higher for all nutrients (except zinc) on HDM days in comparison to NM days.

Degree of nutritional risk. Participants were classified as being at low risk, moderate risk, and high nutritional risk according to the following scale:

$\begin{array}{lll}\text { MAR }>.66 & \text { Low Nutritional Risk } \\ \text { MAR } .50-.66 & \text { Moderate Nutritional Risk } \\ \text { MAR }<.50 & \text { High Nutritional Risk }\end{array}$

A higher number of people were classified as being at low nutritional risk than at moderate and high nutritional risk on both HDM and NM days, although the percentage of low risk was higher on HDM days. According to MARs, $92 \%$ of the sample could be considered to be at low nutritional risk on HDM days, and 78\% at low nutritional risk on NM days. In the moderate nutritional risk category, $6 \%$ were classified on HDM days, and 18\% on NM days. Two percent were 
Table 4

Percentage of Participants with Nutrient Adequacy Ratios (NARS) on Home-Delivered Meal (HDM) Days according to the Scale: Less than $.50, .50-.66, .67-.99,1.00$ and Greater.

NAR

\begin{tabular}{|c|c|c|c|c|c|}
\hline Nutrient & $<.50$ & .50 & -.66 & $.67-.99$ & $1.00+$ \\
\hline Protein & $2 \%$ & & $1 \%$ & $24 \%$ & $73 \%$ \\
\hline Calcium & $14 \%$ & & $14 \%$ & $33 \%$ & $39 \%$ \\
\hline Vitamin A & $16 \%$ & & $12 \%$ & $23 \%$ & $49 \%$ \\
\hline Iron & $4 \%$ & & $5 \%$ & $31 \%$ & $60 \%$ \\
\hline Vitamin C & $6 \%$ & & $7 \%$ & $11 \%$ & $76 \%$ \\
\hline Thiamin & $3 \%$ & & $3 \%$ & $17 \%$ & $77 \%$ \\
\hline Riboflavin & $2 \%$ & & $3 \%$ & $17 \%$ & $78 \%$ \\
\hline Niacin & $2 \%$ & & $9 \%$ & $27 \%$ & $62 \%$ \\
\hline Folacin & $9 \%$ & & $8 \%$ & $6 \%$ & $77 \%$ \\
\hline Vitamin B-6 & $21 \%$ & & $19 \%$ & $26 \%$ & $34 \%$ \\
\hline Vitamin $\mathrm{B}-12$ & $4 \%$ & & $5 \%$ & $10 \%$ & $81 \%$ \\
\hline Zinc & $36 \%$ & & $21 \%$ & $33 \%$ & $10 \%$ \\
\hline
\end{tabular}

Note. Maximum percent $=100 \%$. 
Table 5

Percentage of Participants with Nutrient Adequacy Ratios (NARs) on Non-Meal (NM) Days according to the Scale: Less than $.50, .50-.66, .67-.99,1.00$ and Greater.

NAR

Nutrient

$<.50 \quad .50-.66 \quad .67-.99$

$1.00+$

\begin{tabular}{lrrrr}
\hline Protein & $7 \%$ & $3 \%$ & $29 \%$ & $61 \%$ \\
Calcium & $27 \%$ & $18 \%$ & $25 \%$ & $30 \%$ \\
Vitamin A & $25 \%$ & $12 \%$ & $26 \%$ & $37 \%$ \\
Iron & $8 \%$ & $8 \%$ & $38 \%$ & $46 \%$ \\
Vitamin C & $20 \%$ & $4 \%$ & $11 \%$ & $65 \%$ \\
Thiamin & $9 \%$ & $9 \%$ & $23 \%$ & $59 \%$ \\
Riboflavin & $6 \%$ & $6 \%$ & $22 \%$ & $66 \%$ \\
Niacin & $12 \%$ & $6 \%$ & $25 \%$ & $57 \%$ \\
Folacin & $18 \%$ & $15 \%$ & $29 \%$ & $38 \%$ \\
Vitamin B-6 & $27 \%$ & $16 \%$ & $28 \%$ & $29 \%$ \\
Vitamin B-12 & $10 \%$ & $7 \%$ & $19 \%$ & $64 \%$ \\
Zinc & $37 \%$ & $32 \%$ & $18 \%$ & $13 \%$ \\
& & & & \\
\hline
\end{tabular}

Note. Maximum percent $=100 \%$. 
classified at high risk HDM days, and $4 \%$ on NM days (Table 6). Fourteen percent reported that what they ate and drank on the HDM day was not typical for them, while $25 \%$ reported that what they ate and drank on the NM day was not typical for them.

Food safety. There was no significant correlation between reported home-delivered meal food safety practices and participants' responses to food safety questions, or whether participants' had previously received information on safe food handling. All participants (100\%) reported having refrigerators and ranges, which would allow leftover HDM foods to be stored below 40 degrees $F$ and reheated to temperatures above 145 degrees F. Fifty-nine percent reported that they had not eaten the entire HDM when they received it; however, numbers of people saving HDM foods were low. Nine people reported that they had saved the entree for later consumption, and all nine reported that they had refrigerated the leftovers. Four people reported that they had saved the vegetable for later consumption, and one did not save them in the refrigerator. Nine saved the margarine for later consumption, and three reportedly did not save the margarine in a refrigerator. Twenty-seven saved milk for later consumption. One reportedly did not refrigerate it.

A majority of respondents said they would not taste suspect food and would not be concerned about foods 
Table 6

Percentage of Participants at Low, Moderate, and High Nutritional Risk on Home-Delivered Meal (HDM) and Non-Meal (NM) Days.

Risk

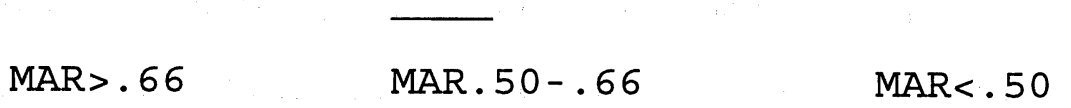

Meal $n$ Low $n$ Moderate $n$ High

\begin{tabular}{lrrrrrr}
\hline $\mathrm{HDM}$ & 93 & $92 \%$ & 6 & $6 \%$ & 2 & $2 \%$ \\
$\mathrm{NM}$ & 79 & $78 \%$ & 18 & $18 \%$ & 4 & $4 \%$ \\
\hline
\end{tabular}

Note. Maximum percent $=100 \%$. 
considered unsafe to eat. When asked the question, "If you suspected that a food 'might have gone bad,' would you taste it to see if it was safe to eat?" Twenty-seven percent said yes. Fifty-nine percent said no, and $14 \%$ were unsure. When asked, "How concerned would you be about eating cooked meat or poultry that had been left out at room temperature for more than 4 hours?" Eighty-five percent said they would be concerned. Twelve percent would not be concerned, and $3 \%$ were unsure. Eighty-six percent said they had previously been supplied with information on the safe handling of foods, and $75 \%$ did not want further information on the safe handling of foods. In addition, Peace Meal staff interviewers reported no previous problems concerning the food safety practices of home-delivered meal clientele. 
Discussion

For the purpose of discussion, the results of this research may be summarized as follows: (1) Nutrient intakes of the sample, for the nutrients: protein, calcium, vitamin A, iron, vitamin C, thiamin, riboflavin, niacin, folacin, and vitamin B-12 more nearly met the Recommended Dietary Allowances for adults 51 years and older on days of homedelivered meals in comparison to days of no meal delivery. (2) Most participants were considered to be at low nutritional risk on both the days of home-delivered meals and on days of no meal delivery. However, the degree of moderate and high nutritional risk was higher on non-meal delivery days. (3) Individual nutrients identified as of concern due to low consumption by participants were zinc, calcium, vitamin A, and vitamin B-6 on both home-delivered meal and non-meal days, and vitamin $C$, folacin, and niacin on non-meal days only. (4) Over half of the participants reportedly did not consume the entire home-delivered meal soon after receipt, but most participants reported that they did not leave foods out at room temperature. (5) some participants indicated that they would taste a food even if they suspected that it "might have gone bad". Some participants indicated that they would not be concerned about eating cooked meat or poultry left out at room temperature for more than four hours. (6) Most reportedly had been supplied with information on food safety, and most 
did not want any further information.

Nutrient intakes. As adults age, energy requirements and intakes usually decrease; however, nutrient needs remain relatively unchanged (Blumberg, 1992; Schlenker, 1992;

Horwath, 1991; Wurtman et al., 1988). Thus, in order to meet Recommended Dietary Allowances, for adults 51 years and older, aging persons must consume more nutrient-dense foods. Therefore, many old-old and oldest-old people have difficulties in meeting nutrient requirements (Fischer \& Johnson, 1990). In this study, it was expected that younger participants would have diets which would more closely meet the RDAs on HDM and NM days in comparison to older participants. However, age was not significantly related to reported dietary intake.

According to some studies, nutrient intakes tend to differ between the two genders. In some studies, women had significantly higher intakes of vitamin C (Jacob et al., 1988), and of folacin and vitamin A (Posner et al., 1987) than did men. Results of the current study revealed that men had intakes more nearly meeting the RDAs for iron and niacin in comparison to women. These results would agree with findings from Hatangady-Mahajan \& Schafer (1993) who found that men had higher intakes of iron, niacin, calcium, thiamin, and riboflavin.

In many instances, people who live alone eat alone. In the present study, living arrangement had no significant 
affect on nutrient intakes, even though numerous studies have noted that living arrangement may affect nutrient intake. Living alone was correlated with meal skipping (Davis et al., 1988), and with nutrient intakes below recommendations (Davis et al., 1990). Eating alone was associated with lower intakes of macro and micronutrients (DeCastro \& DeCastro, 1989; McIntosh et al., 1989). However, as noted by Troll (1971), residential isolation may be less important than communicative isolation. In other words, if a person lived with other people but had no interaction with them, that person may be more effectively isolated than if a person lived alone but maintained interaction with others. Thus, it must be noted that there are "desolates," those who live alone and don't like it, and "isolates," those who live alone and like it. The extent to which desolation and isolation affect nutrient intake may be an important issue.

Mean nutrient intakes were significantly higher on HDM days in comparison to NM days for the nutrients: protein, calcium, vitamin A, iron, vitamin C, thiamin, riboflavin, niacin, folacin, and vitamin B-12. These findings were very consistent with those of Kohrs et al. (1978), in which congregate meal participants had significantly higher intakes of energy, protein, calcium, riboflavin, and niacin. Mean Dietary intake of zinc was the lowest in comparison to the RDAs. The percentage was highest for participants 
having NARs less than .50 for the nutrient zinc. Kohrs (1982) noted that zinc is consumed by older persons at about eight to nine mg per day, which is only about $60 \%$ of the $1989 \mathrm{RDA}$ of $15 \mathrm{mg}$. In the study by Garry et al. (1982), $21 \%$ of men and $47 \%$ of women 60 years and older had diets with less than $50 \%$ of the RDA for zinc. The present study is similar to others in which zinc has consistently been identified as a problem nutrient.

This study assessed the mean intake of 12 nutrients. In this study, mean intakes of participants were classified by use of the Mean Adequacy Ratio equation:

\section{Sum of the 12 NARs}

Then, MARs were classified as follows: (1) Low Nutritional Risk $=$ MAR $>.66$ (2) Moderate Nutritional Risk = MAR .50 .66 and (3) High Nutritional Risk $=$ MAR $<.50$.

Using this system described earlier, the present study classified $92 \%$ of the participants at low nutritional risk on HDM days, and $78 \%$ at low nutritional risk on NM days. In some other studies, different criteria were used. For example, all nutrients had to be higher than $66 \%$ in order have a "good" diet (Dow, 1977; Brown, 1979). This is a main reason for the differences in percentages between this study and the other two. In Dow's study (1977), 40\% had diets classified as good. In a study by Brown (1979), 70\% had diets classified as good. However, there has never been a 
set standard for classifying or categorizing diets in this country. Diet is just one factor in identifying and treating nutritional problems in older persons. The Nutrition Screening Initiative (Posner et al., 1993) developed an 11 item checklist in which a score of six or higher defined a person at high nutritional risk. Factors defining nutritional risk included illness, number of meals eaten per day, consumption of fruits and vegetables, consumption of milk, consumption of alcohol, problems chewing or swallowing, eating alone, medication, physical movement, weight-loss, and money for food.

More than ten percent of the participants had NARs less than .50 on HDM days for calcium, vitamin A, vitamin B-6, and zinc. Asp \& Darling (1988) found that 54\% of the sample had calcium intakes less than $67 \%$ of the RDA, and none of the sample had vitamin A intakes less than $67 \%$ of the RDA. More than ten percent of the sample had NARs less than .50 on NM days for calcium, vitamin A, vitamin C, niacin, folacin, vitamin B-6, and zinc. In the study of homebound older persons by Posner et al. (1987), 39\% of the sample failed to meet the RDA for vitamin $A, 33 \%$ failed to meet the RDA for vitamin C, $84 \%$ failed to meet the RDA for calcium, and 59\% failed to meet the RDA for niacin. Garry et al. (1982) found that the following percentage of subjects had diets less than 50\% of the RDAs: no men and two percent of women for vitamin $C$, five percent of men and 
four percent of women for vitamin A, nine percent of men and $12 \%$ of women for calcium, $54 \%$ of men and $61 \%$ of women for vitamin B-6, no men and women for niacin, and $37 \%$ of men and 43\% of women for folacin. Thus, studies show for the most part that participants are not meeting the RDAs for calcium, vitamin A, vitamin C, vitamin B-6, niacin, and folacin. However, percentages of people not meeting the RDAs vary.

The percentage of participants with nutrient intakes less than .50 is lower for all nutrients on HDM days in comparison to NM days. The percentage of participants with nutrient intake at 1.00 or greater is higher for all nutrients (except zinc) on HDM days in comparison to NM days. Thus, the diets of participants are more closely meeting the RDAs on HDM days. In the study by Brown (1979), $70 \%$ of regular congregate meal participants and only $46 \%$ of non-participants had diets which were classified as good, all nutrients meeting at least $67 \%$ of the RDAs.

Food safety. In this present study, all participants had refrigerators, which would allow leftovers to be stored at safe temperatures of below 40 degrees F. Ninety-eight percent of the participants reportedly began to eat their home-delivered meal within a two hour period. Fifty-nine percent of the sample reported that they had not consumed the entire HDM. This percentage differed considerably from one other study in which none of the sample $(n=108)$ consumed the entire meal immediately at all times of delivery over a 
one week period, and only $21 \%$ consumed the entire meal for at least one home-delivered meal for the one week period (Lau, Coleman, \& Krondl, 1994).

To date, no published studies have tracked food safety practices concerning refrigeration of leftovers from homedelivered meals. Immediate refrigeration retards bacterial growth at a higher rate compared to leaving foods out at room temperatures for different time intervals (Black \& Lewis, 1948). In this present study, some protein food leftovers were left out unrefrigerated, but it was difficult to determine whether those items were consumed within a period of four hours or greater. There was no correlation between food safety questions and reported practices. Also, the Peace Meal staff had not observed any previous food safety problems in other home-delivered meal clientele. However, it is worth noting that some participants did either report that they would taste a food (27\%) or were not sure about tasting a food (14\%) even if they suspected that it "might have gone bad." Thus, $41 \%$ either would or might taste a suspected food. Also, $12 \%$ would not be concerned and $3 \%$ were unsure whether they would be concerned about eating cooked meat or poultry left out at room temperature for more than four hours. Thus, 15\% would be unconcerned or unsure about this aspect of food safety. 
It is noteworthy that the Peace Meal program routinely checks and documents temperatures of congregate and home-delivered meals. Also, during home assessments, the Peace Meal staff carefully documents, monitors, and works to eliminate food safety problems. Such careful monitoring may not exist in all home-delivered meal programs.

Overall, it appears that most participants are at low nutritional risk on HDM (92\%) and NM (78\%) days according to mean intakes. However, older persons at moderate and high nutritional risk need to be identified and helped. Homedelivered meals are improving the diets of a considerable number of older persons. Thus, it would be very important to increase the number of meals to homebound elderly. Nutrients identified as a concern due to low consumption by participants were zinc, calcium, vitamin A, and vitamin B-6 on both HDM and NM days, and vitamin C, folacin, and niacin on NM days only. Therefore, zinc, calcium, vitamin A, and vitamin B-6 should be increased in Title III-C meals. Over half of the participants (59\%) reportedly did not consume the entire HDM promptly, but most were refrigerating the leftovers. Some participants reported that they would taste $(27 \%)$ or were unsure $(14 \%)$ about tasting a food that they suspected "might have gone bad." Some would not be concerned $(12 \%)$ or were unsure $(3 \%)$ about eating cooked meats or poultry left out at room temperature for more than four hours. Most ( $86 \%$ ) had previously been supplied with 
food safety information, and most (75\%) did not want any further information. Therefore, it would be very important to further explore delayed consumption patterns in home-delivered meals, and food safety concerns. 
CHAPTER 5

SUMMARY, CONCLUSION, IMPLICATIONS

The purposes of this study were to assess the diets of those receiving home-delivered meals in a Title III-C nutrition program both on a day of meal delivery and day of non-meal delivery, and to assess some food safety practices of the sample.

The three objectives were as follows: (1) to compare the diets of participants receiving Home-Delivered Meals to the Recommended Dietary Allowances for the following nutrients: protein, calcium, vitamin A, iron, vitamin C, thiamin, riboflavin, niacin, folacin, vitamin B-6, vitamin B-12, and zinc on a weekday (day of meal delivery) and on a weekend (no meal delivery) based on participants' 24-hour recalls; to compare the dietary intakes of participants' weekday diets to week end diets based on 24-hour recalls; and (3) to examine some food safety practices of participants in relation to Home-Delivered Meals.

Date were collected from a sample of 101 older adults receiving home-delivered meals. Two interviews of each adult were conducted by trained interviewers using a multi-part questionnaire. All answers were recorded on a corresponding record sheet. The questionnaire contained 16 items designed to obtain demographic information, dietary information, and limited food safety practices. Additional demographic information and the home-delivered menu were recorded on the 
record sheet.

The results of the study indicated that diets were improved on HDM days in comparison to NM days, when comparing nutrient intakes to Recommended Dietary Allowances for Americans 51 years and older. Most participants could be classified as being at low nutritional risk according to their Mean Adequacy Ratios, reflecting their intake of 12 nutrients. Most reportedly were refrigerating the leftovers from the meals. Forty-one percent of the participants reported that they would taste food, or were unsure whether they would taste food, even if they suspected that it "might have gone bad." Fifteen percent reported that they either would not be concerned, or were unsure, about eating meat or poultry left out at room temperature for more than four hours. Most have received information on the safe handling of foods, and most do not want any further information.

\section{Limitations}

There were several limitations of the study:

1. The sample were lucid, long-term participants selected by the Peace Meal staff, and were drawn from a population of Peace Meal, home-delivered meal recipients. Thus, the sample may not have been a true representation of the population.

2. Five people interviewed participants in the study, and even with training, perfect interrater reliability was not possible. 
3. The 24-hour recall does not completely control for under or overreporting, or lapses of memory. The 24hour recall is not necessarily a true representation of typical diet.

4. The Nutritionist III (1988) computer program has a standard list of foods. Some foods listed in the 24hour recalls had to be entered according to foods most closely related.

5. Responses to the surveys were all self-reported. Self-reporting may not have always been accurate, especially regarding foods consumed or saved from the home-delivered meals.

\section{Conclusions}

1. The diets of homebound older persons, age 60 and older, are more closely meeting the Recommended Dietary Allowances, for adults 51 years and older, on days a home-delivered meal is served.

2. Low zinc intake is a concern in older persons. Also, intakes of calcium, vitamin A, and vitamin B-6 are somewhat of a concern both on HDM and NM days. Vitamin C, niacin and folacin intake are also somewhat of a concern on NM days.

3. Some older persons are at moderate and high nutritional risk, although there has never been a valid standard for classifying nutrient intakes. 
62

4. The majority of lucid, long-term recipients of homedelivered meals in this program have knowledge about proper safe handling of foods and practice safe handling of foods from home-delivered meals.

\section{Implications}

1. Home-delivered meals are providing a valuable service to older Americans, and means to provide such meals to all those who need them should be explored.

2. The nutrient analysis of Peace Meal menus is figured on a one-week basis and does comply with the RDAs. Even so, the content of zinc, calcium, vitamin A, and vitamin B-6 should be targeted as nutrients of concern in Title III-C meals. Education to increase zinc intake in older persons should be investigated. Other nutrients which should be targeted as a concern in older persons are vitamin C, niacin, and folacin.

3. There needs to be a validated standard for classifying the nutrient intakes of older persons in comparison to the RDAs.

4. Further research should explore and develop ways to decrease the risk of malnutrition in targeted individuals. 
5. Further research should explore delayed consumption patterns of home-delivered meals, especially concerning food safety practices, and possible ways to correct delayed consumption patterns and food safety problems. 


\section{REFERENCES}

ADA take proactive stance, testifies on Older Americans Act reauthorization. (1984). Journal of American Dietetic Association, 84, 822-835.

Arnet, J.W., \& Zahler, L.P. (1993). Dietary and health habits of healthy, retired, elderly men. Journal of Nutrition for the Elderly, 12, 43-56.

Aronow, W.S. (1993). Serum ferritin is not a risk factor for coronary artery disease in men and women aged $\geq 62$ years. American Journal of Cardiology, 72, 347-34 8 .

Asp, E.H., \& Darling, M.E. (1988). Home-delivered meals: food quality, nutrient content, and characteristics of recipients. Journal of the American Dietetic Association, 88, 55-59.

Bauman, H.E. (1974). The HACCP concept and microbiological hazard categories. Food Technology, September, 30-34.

Black, L.C. \& Lewis, M.N. (1948). Effect of bacterial growth by various methods of cooling cooked foods. Journal of the American Dietetic Association, 24, 399404 .

Blumberg, J.B. (1992). Changing nutrient requirements in older adults. Nutrition Today, September-October, 1520 .

Brown, A. (1986). FDA expands potentially hazardous food definition. Journal of Environmental Health, 49, 46.

Brown, E.L. (1976). Factors influencing food choices and intake. Geriatrics, September, 89-91.

Brown, M.S. (1979). Socio-psychological factors affecting dietary intake of non-instititutionalized rural elderly. (Doctoral dissertation, Florida state University). Dissertation Abstracts International, $\underline{40}, 3004-\mathrm{B}$.

Burt, M.R. (1993). Hunger among the elderly: local and national comparisons. (Project Report). Washington, DC: The Urban Institute.

Consenses Development Conference: Diagnosis, Prophylaxis, and Treatment of Osteoporosis. (1993). American Journal of Medicine, 94, 646-649. 
Couzy, F., Kastenmayer, P., Mansourian, R., Guichard, S., Munoz-Box, R., \& Dirren, H. (1993). Zinc absorption in healthy elderly humans and the effect of the diet. American Journal of Clinical Nutrition, 58, 690-694.

Davis, M.A., Murphy, S.P., \& Lein, D. Living arrangements and dietary quality of U.S. adults. Journal of the American Dietetic Association, 90, 1667-1672.

Davis, M.A., Murphy, S.P., \& Neuhaus, J.M. (1988). Living arrangements and eating behaviors of older adults in the United States. Journal of Gerontology, 43, S96S98.

Davis, M.A., Randall, E., Forthofer, R.N., Lee, E.S. \& Margen, S. (1985). Living arrangements and dietary patterns of older adults in the United States. Journal of Gerontology, 40, 434-442.

DeCastro, J.M., \& DeCastro, E.S. (1989). Spontaneous meal patterns of humans: influence of the presence of other people. American Journal of Clinical Nutrition, 50, $237-247$.

Dow, R. (1977). How well do seniors eat? Title VII can help. Aging, 274, 12-14.

Dow, R. (1977). National adequacy of the diets of some elderly congregate meal participants, Unpublished manuscript, Eastern Illinois University, Peace Meal Program, Charleston.

Doyle, M.P. (1993). Reducing foodborne disease - what are the priorities? Nutrition Review, 51, 346-347.

DPGs collect data for ADA testimony: effect of DPGs on demand for home-delivered meals. (1985). Journal of the American Dietetic Association, 85, 1638-1639.

Edwards, D.L., Frongillo, E.A., Rauschenbach, B., \& Roe, D.A. (1993). Home-delivered meals benefit the diabetic elderly. Journal of the American Dietetic Association, 93, $585-586$.

Fischer, J., \& Johnson, M.A. (1990). Low body weight and weight-loss in the aged. Journal of the American Dietetic Association, 90, 1697-1706.

Garry, P.J., Goodwin, J.S. Hunt, W.C., Hooper, E.M., \& Leonard, A.G. (1982). Nutritional status in a healthy elderly population: dietary and supplemental intakes. American Journal of Clinical Nutrition, 36, 319-331. 
Gordon, S.R., Kelly, S.L., Sybyl, J.R., Mill, M., Kramer, A. , \& Jahnigen, D. (1985). Relationship in very elderly veterans of nutritional status, self-perceived chewing ability, dental status and social isolation. Journal of the American Geriatrics Society, 33, 335339 .

Guthrie, H. (1990). Recommended Dietary Allowances 1989: changes, consensus, and challenges. Nutrition Today, Jan./Feb., 43-45.

Guthrie, H.A., \& Scheer, J.C. (1981). Validity of a dietary score for assessing nutrient adequacy. Journal of American Dietetic Association, 78, 240-245.

Harris, B., Woteki, C., Briefel, R.R., \& Kleinman, J.C. (1989). NHANES III for older persons: nutrition content and methodological considerations. American Journal of Clinical Nutrition, 50, 1145-1149.

Hattangady-Mahajan, K., \& Schafer, E. (1993). Influence of selected psychosocial factors on dietary intake in the elderly. Journal of Nutrition for the Elderly, 12, 2139 .

Howarth, C.C. (1991). Nutrition goals for older adults: a review. The Gerontologist, 31, 811-819.

Hutton, C.W. \& Hayes-Davis, R.B. (1983). Assessment of the zinc nutritional status of selected elderly subjects. Journal of American Dietetic Association, 82, 148-152.

Jacob, R.A., Otradovec, C.L., Russell, R.M., Munro, H.N., Hartz, S.C., McGandy, R.B., Morrow, F.D. \& Sadowski, J.A. (1988). Vitamin $C$ status and nutrient interactions in a healthy elderly population. American Journal of Clinical Nutrition, 48, 1436-1442.

Joosten, E., van den Berg, H., Riezler, R., Naurath, H.J., Lindenbaum, J., Stabler, S.P., \& Allen, R.H. (1993). Metabolic evidence that deficiencies of vitamin b-12, (cobalamin), folate, and vitamin b-6 occur commonly in elderly people. American Journal of Clinical Nutrition, 58, 468-476.

Karvetti, R.L., \& Knuts, L.R. (1985). Validity of the 24hour dietary recall. Journal of American Dietetic Association, 85, 1437. 
Kohrs, M.B., O'Hanlon, P., \& Eklund, D. (1978). Title VII nutrition program for the elderly. Journal of American Dietetic Association, 72, 487-492.

Korhs, M.B. (1982). Evaluation of nutrition programs for the elderly. American Journal of Clinical Nutrition, (Suppl. 36), 812.

Krasinski, S.D., Russell, R.M., Otradovec, C.L., Sadowski, J.A., Hartz, S.C., Jacob, R.A., \& McGandy, R.B. (1989). Relationship of vitamin $A$ and vitamin $E$ intake to fasting plasma retinol, retinol-binding protein, retinyl esters, carotene, alpha-tocopherol, and cholesterol among elderly people and young adults: increased plasma retinyl esters among vitamin A supplement users. American Journal of Clinical Nutrition, 49, 112-119.

Krebs-Smith, S.M. \& Clark, D.C. (1989). Validation of a nutrient adequacy score for use with women and children. Journal of American Dietetic Association, 89, 775-780, 783.

Lau, D., Coleman, P., \& Krondl, M. (1994). Delayed consumption patterns of home-delivered meals by elderly recipients $75+$ years. Journal of American Dietetics Association, (Suppl. 94), A-61.

Madden, J.P., Goodman, S.J., \& Guthrie, H.A. (1976). validity of the 24-hour recall: analysis of data obtained from elderly subjects. Journal of American Dietetic Association, 68, 143.

Manore, Vaughan, L.A., Carroll, S.S. \& Laklem, J.E. (1989). Plasma pyridoxal 5-phosphate concentration and dietary vitamin b-6 intake in free-living, low-income elderly people. American Journal of Clinical Nutrition, 50, $239-245$.

McIntosh, W.A., Shifflet, P.A., \& Piccou, J.S. (1989). Social support, stressful events, strain, dietary intake, and the elderly. Medical Care, 27, 140-153.

National Research Council. (1980). Recommended Dietary Allowances, (ninth ed.). Washington, DC: The National Academy of Sciences.

National Research Council. (1989). Recommended Dietary Allowances, (10 th ed.). Washington, DC: The National Academy of Sciences. 
Older American Act Passes. (1992). Journal of American Dietetic Association, 92, 1458 .

Pannemans, D.L., van den Berg, H., \& Westerterp, K.R. (1994). The influence of protein intake on vitamin b6 metabolism differs in young and elderly humans. Journal of Nutrition, 124, 1207-1214.

Popkin, B.M., Haines, P.S., \& Patterson, R.E. (1992). Dietary changes in older Americans, 1977-1987. American Journal of Clinical Nutrition, 55, 823-830.

Posner, B.E., Jette, A.M., Smith, K.W., \& Miller, D.R. (1993). Nutrition and health risks in the elderly: the nutrition and screening initiative. American Journal of Public Health, 83, 972-977.

Posner, B.E., Smigelski, C.G., \& McLaren-Krachenfels, M. (1987). Dietary characteristics and nutrient intake in an urban homebound population. Journal of American Dietetic Association, 87, 452-456.

Ryan, V.C., \& Bower, M.E. (1989). Relationship of socioeconomic status and living arrangements to nutritional intake of the older person. Journal of American Dietetic Association, 89, 1805-1807.

Salonen, J.T., Nyssonen, K., Korpela, H., Tuomilehto, J., Seppanen, R., \& Salonen, R. (1992). High stored iron levels are associated with excess risk of myocardial infarction in Eastern Finnish men. Circulation, 86, $803-811$.

Schlenker, E. (1992). Nutrition for the aging and the aged. In S. Rodwell-Williams \& B.S. Worthington-Roberts (Ed.), Nutrition Throughout the Lifecycle. (pp. 344385). St. Louis, Mo: Mosby-YearBook, Inc.

Spitzer, M.E. (1988). Taste acuity in institutionalized and noninstitutionalized elderly men. Journal of Gerontology, 43, 71-74.

SPSS Release 4.1 for IBM VM/CMS. (1994). Educating Computing Network.

Stevens, D.A., Grivetti, L.E., \& McDonald, R.B. (1992). Nutrient intakes of urban and rural elderly receiving home-delivered meals. Journal of American Dietetic Association, 92, 350-382. 
Ten State Nutrition Survey 1968-1970. (1972). (DHEW Publication No. (HSM) 72-8130-33. Atlanta Dept. of Health Education, and Welfare, Health Service and Mental Health Administration). Atlanta, GA: Center for Disease Control.

Thole, C., \& Gregoire, M.B. (1992). Time-temperature relationships during freezing of packaged meals in feeding programs for the elderly. Journal of American Dietetic Association, 92, 350-352.

Troll, L.E. (1971). Eating and aging. Journal of the American Dietetic Association, 59, 456-459.

US Senate Special Committee on Aging: Aging America: trends and projections. (1988). Washington DC: US Government Printing Office.

Vanderjadt, D.J., Garry, P.J., \& Bhagavan, H.N. (1987). Ascorbic acid intake and plasma levels in healthy elderly people. American Journal of Clinical Nutrition, 46, 290-294.

Wells, C.F. (1973). Nutrition programs under the older Americans Act. American Journal of Clinical Nutrition, 26, 1127-1132.

West, B., \& Wood, L. (1988). Food Service Institutions, (sixth ed.). New York, NY: Macmillan Publishing Co.

Williamson, D.M., Gravani, R.B., \& Lawless, H.T. (1992). Correlating food safety knowledge with home foodpreparation practices. Food Technology, May, 94-98.

Wurtman, J.J., Lieberman, H., Tsay, R., Nader, T., \& Chew, B. (1988). Calorie and nutrient intakes of elderly and young subjects measured under identical conditions. Journal of Gerontology, 6 , B174-B180.

Zipp, A., \& Holcolmb, C.A. (1992). Living arrangements and nutrient intakes of healthy women age 65 and older: a study in Manhattan, Kansas. Journal of Nutrition for the Elderly,11, 1-15. 
Appendix A

Hello, Mr./Miss/Mrs.

My name is I am Ifrom the Peace Meal Senior Nutrition Program, or Graduate student at Eastern Illinois University school of Home Economics). We are doing a research study about the diets of people receiving home-delivered meals through the Peace Meal program. Would it be all right if I ask you some questions, mostly about what you eat? We plan to write some reports, but your name will never be used.

\section{ASK ONLY ON FIRST VISIT (SECTION A):}

1. How tall are you?

2. How much do you weigh?

3. Are you taking any vitamin or minerals supplements? If so, which ones do you take?

4. Do you cook for yourself?

5. Are meals provided for you at home in addition to the Peace Meal, for example, does a friend or family member provide meals for you? If yes, by whom? how often?

6. Do you have:

a refrigerator? freezer? stove? microwave?

[hot plate? ask only if do not have a stove] 


\section{ASK AT BOTH VISITS (SECTION B):}

7. Can you tell me if you had anything to eat yesterday morning? If so, what did you eat? Can you tell me if you had anything to drink yesterday morning? If so, what did you drink? [If participant calls a meal by name, then use those names.]

How many?

How many cups/glasses/ounces/pieces?

How was this prepared (fresh, fried, baked, broiled, homemade, package, or mix)?

[Use models, glasses, spoons]

[If condiments are common with the items mentioned, ask did you have anything on your hamburger, sandwich, etc.? Also ask, Did you have anything in your coffee?]

8. After you ate [breakfast or what you just told me about], when did you next have something to eat or drink? (time). Please tell me what you ate? Please tell me what you drank? (see \#7 above)

[Continue through the day until no more foods/beverages are reported.]

9. Was this a pretty typical day for you as far as what you ate and drank? If not, how was it different?

\section{ASK ONLY DAY AFTER PEACE MEAL DAY (SECTION C) :}

10. After your Peace meal arrived yesterday, how soon did you eat it?

less than 2 hrs.

$2-4$ hrs

more than 4 hrs.

11. After your Peace Meal arrived yesterday, did you eat all of the meal?

yes

no If no, then 12: 
12. Did you eat all of the (entree of "yesterday's Peace Meal) at the time it was delivered?

yes If yes, then repeat question 12 for next item on "yesterday's" Peace Meal

no If no, then $12 \mathrm{a}$ :

12a. Did you save any or all of the (entree/next item) and :

later throw it away

or

eat it later if so, then go to $12 \mathrm{~b}$

12b. Did you later eat the (entree/next item):

within 4 hours after delivery--go to $12 \mathrm{C}$

more than 4 hours after delivery--go to $12 \mathrm{C}$

12c. Did you store the (entree/next item) in a refrigerator after it was delivered until the time you ate it?

yes

no 


\section{ASK ONLY ON FIRST VISIT (SECTION D) :}

13. If you suspected that a food might "have gone bad", would you taste it to see if it was safe to eat? yes no not sure

14. How concerned would you be about eating cooked meat or poultry that had been left at room temperature for more than 4 hrs.?

concerned

not concerned not sure

15. Have you ever been given information on the safe handling of foods in order to prevent illnesses which may be caused by food?

yes no

16. Would you like information on the safe handling of foods?

yes no 
Appendix B

Permission

1. Ht .

yes

2. WE.

3. Vitamins: mult. other Minerals: $\mathrm{Fe} \mathrm{Ca}$ oth

4. Cook for sel $\bar{f}$ : yes no

no

Meals provided for you

in addition to Peace Meal? yes no who? how often?

Code No.

Name

Address

Phone

Date

No. in household

PEACE MEAL MENU

friends

family

- neighbor

- other

6. Do you have? refrig. hot plate

freezer stove microwave

7. \& 8 .

Food/Drink Consumed Morning Meal

Amt. (Cups, tsp., Tbsp., oz .)

Between Meals 
Food/Drink Consumed

Amt. (Cups, tsp. , Tbsp . , oz .)

Mid-day Meal

\section{Between Meals}

\section{Evening Meal}

\section{Later Food/Drink}

9. Typical yes no Explain

10. After your Peace Meal arrived, how soon did you eat it? less than 2 hrs._ 2-4 hrs._ greater than 4 hrs.

11. After your Peace $\bar{M}$ eal arrive $\bar{d}$ did you eat all of the meal?

yes__ no


12. If the answer is no, then continue:

Consumed: If some: If saved:

If not disc, :

all some discard. saved disc. atein ate stored in ref. 4 hrs. >4hrs. yes

no

PRO

Veg\# 1

Veg\#2

Bread

Fruit

Marg.

Dessert

Milk

13. If you suspected that a food might "have gone bad", would you taste it to see if it was safe to eat? yes no not sure

14. How concerned would you be about eating cooked meat or poultry that had been left at room temperature for more than 4 hrs.?

$$
\text { concerned }
$$

not concerned

not sure

15. Have you ever been given information on the safe handling of foods in order to prevent illnesses which may be caused by food? yes no

16. Would you like information on the safe handling of foods?

yes

no 